Article

\title{
China's Contributions to Global Green Energy and Low-Carbon Development: Empirical Evidence under the Belt and Road Framework
}

\author{
Hongze $\mathrm{Li}^{1,2}$, FengYun $\mathrm{Li}^{1, *}$ and Xinhua $\mathrm{Yu}^{1}$ \\ 1 School of Economics and Management, North China Electric Power University, Beijing 102206, China; \\ lihongze@ncepu.edu.cn (H.L.); yuxinhua@ncepu.edu.cn (X.Y.) \\ 2 Beijing Key Laboratory of New Energy and Low-Carbon Development, North China Electric Power \\ University, Beijing 102206, China \\ * Correspondence: flash3wade@foxmail.com
}

Received: 24 May 2018; Accepted: 8 June 2018; Published: 12 June 2018

\begin{abstract}
This paper aims to explore China's contributions to global green energy and low-carbon (GELC) development based on the Belt and Road (B\&R) Initiative. Basic situations of B\&R countries reveal an urgent requirement for developing green energy. Carbon intensity is an efficient indicator reflecting the degree of GELC development, which is affected by many factors. By analyzing the spatial distribution of carbon intensities in $29 \mathrm{~B} \& \mathrm{R}$ countries excluding China, the spatial agglomeration and positive radiation effects are discovered, while the negative radiation effects are disappearing, indicating that the studied $B \& R$ countries lack an effective driving mechanism to promote GELC development. Besides, the spatial convergence results support significant absolute and conditional convergences in the $29 \mathrm{~B} \& \mathrm{R}$ countries, and a faster convergence speed when considering control variables. Therefore, $B \& R$ countries trend to converge to a steady stable carbon intensity to achieve the GELC development. Furthermore, the investment rate and openness play a driving role in pushing the decrease of carbon intensity growth rate, revealing that the B\&R Initiative can promote reducing the global carbon emissions and developing global green energy. Moreover, the carbon intensity of the country will be positively affected by those of the surrounding areas, indicating that reducing carbon emission is a global governance issue requiring the participation of all countries. Finally, several policy suggestions are proposed to promote the global GELC development under B\&R framework, according to the empirical findings.
\end{abstract}

Keywords: green energy and low-carbon development; China's contributions; Belt and Road framework; spatial panel econometric methods

\section{Introduction}

Climate warming has become the most serious environmental problem in the world, posing a huge threat to the survival and development of humankind. The main reason for this issue is the dramatic increase in carbon emissions due to the lack of green energy consumption in recent years. The United Nations Framework Convention on Climate Change (UNFCCC), which was the first international convention aiming to comprehensively control the emission of greenhouse gases such as carbon dioxide $\left(\mathrm{CO}_{2}\right)$ and respond to climate change and developing green energy, was released in 1992 [1]. In 1997, of the Global Climate Conference held in Japan, the adoption of the report Kyoto Protocol further demonstrated the determination of all countries to work together to complete energy-saving and emission reduction [2]. At the conference, countries proposed the international emissions trading mechanism, the joint implementation mechanism and the green energy development mechanism to achieve greenhouse gas emission reduction goals. Raising carbon productivity is at 
the core of developing a low-carbon economy and is also a key countermeasure to cope with climate change under the framework of GELC development [3]. Thus, it is of great significance to reduce carbon emissions, which is an important reflection of GELC development.

The GELC development, meaning that green energy should be used as much as possible in production and life to reduce the burning of carbon-containing substances, thereby reducing $\mathrm{CO}_{2}$ emissions and slowing ecological deterioration and greenhouse effects, was first proposed by the United Kingdom [4]. With the increasing seriousness of climate problems, countries around the world have shown great interest in the GELC development and have issued corresponding policies to promote it. Specifically, the United States successively promulgated the Low-carbon Economical Act [5] and The American Clean Energy and Security Act [6], striving to develop low-carbon technologies by relying on its technological and market advantages in energy efficiency and renewable energy, which can help the United States to fundamentally dominate the future development of the world economy. Meanwhile, Japan and European Union countries have also formulated many GELC development policies, such as Action Plan for Realizing Low-carbon Society of Japan in 2008 [7], Roadmap 2050: a practical guide to a prosperous, low-carbon Europe promulgated by European Union in 2010 [8], Climate Change Act of United Kingdom in 2008 [9], French National Low-carbon Strategy in 2015 [10] and German Renewable Energy Act in 2008 [11]. The implementation of these policies has greatly promoted the global GELC development. In 2017, the United States withdrew from the Paris Agreement, but the GELC development has become a global consensus, so this act of the United States has not had major impacts on the global GELC development [12].

In September and October of 2013, China successively proposed a major initiative to jointly build the "Silk Road Economic Belt" and "21st Century Maritime Silk Road" (Belt and Road, B\&R), which have been highly recognized by the international community $[13,14]$. The B\&R Initiative involves 66 countries in Asia, Europe and Africa, but the cooperation is not limited to these countries. The countries along the B\&R (excluding China) accounted for $46.3 \%, 24.8 \%, 42.8 \%$ and $43.6 \%$ of the world's total population, GDP, energy consumption and electricity consumption, respectively [15], indicating that the economic development and energy market in B\&R countries have great potential. The B\&R Initiative involves energy, transportation, trade, services, finance, and other fields, of which "energy first" is the important foundation and support for B\&R because the production and life of modern society depend on energy heavily.

In March 2015, National Development and Reform Commission (NDRC), Ministry of Foreign Affairs (MFA) and the Ministry of Commerce (MC) jointly announced the Vision and Action for the Promotion of the Silk Road Economic Belt and the 21st Century Maritime Silk Road [16], clearly stating that "strengthening the green and low-carbon construction and operation management of infrastructure, taking full account of the impact of climate change during construction", showing that China will highlight the concepts of ecological civilization, ecological environment and biodiversity, and cope with climate change cooperation to jointly build the Green Silk Road in the international investment and trade. On the eve of the B\&R International Cooperation Summit Forum in 2017, the Ministry of Environmental Protection (MEP), MFA, NDRC and MC issued the Guiding Opinions on Promoting the Construction of the Green Belt and Road [17], which focused on several global issues such as routine environmental pollutions, climate change and GELC development.

The B\&R green energy development should closely follow the pulse of the current world energy revolution and grasp the development laws from high carbon to low carbon, from low efficiency to high efficiency and with partial balance to large-scale configuration [18]. The carbon emission intensity of fossil energy is high, and the development and utilization of fossil energy have continued for hundreds of years, emitting a large amount of $\mathrm{CO}_{2}$ and affecting the global climate [19]. To mitigate climate change and achieve GELC development, we must reduce the proportion of fossil energy in the energy structure and increase the proportion of green energy. The main energy in most $B \& R$ countries is fossil energy, and the development and utilization of abundant green energy are limited, as showed in Figure 1. The future trends of energy development are the gradual reduction of fossil 
energy and the gradual increase of green energy [20]. According to the B\&R GELC development principles, when realizing the transformation of traditional fossil energy with high efficiency and low carbon, we must accelerate the large-scale development and utilization of green energy and optimize the energy structure, avoiding the astray of developed countries that converting to green energy after fossil energy is highly developed [21].

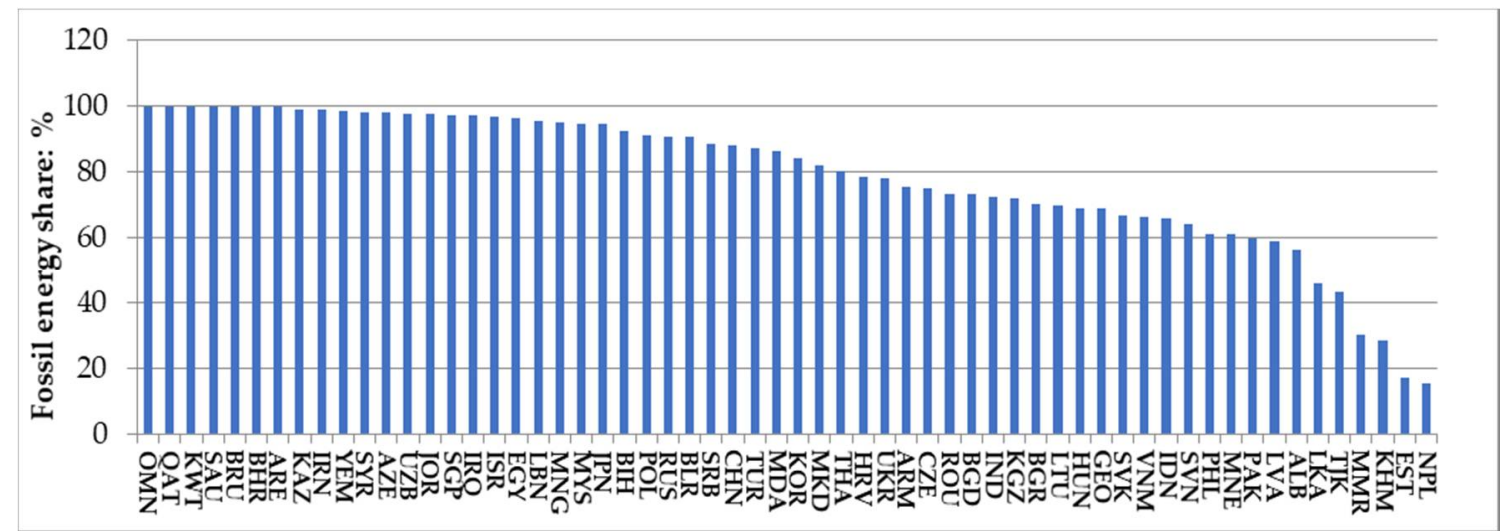

Figure 1. Percentage of fossil energy consumption in major B\&R countries in 2014.

With the increasing competition of international resources and energy, countries have fully realized the strategic position of raw materials and energy, which make developing countries more willing to undertake GELC industries. Therefore, the establishment of a resource-saving and environment-friendly international industrial transfer mechanism becomes an important trend for international industrial transfer in the future [22]. Under the B\&R Initiative, China focused its attention on the three dimensions of coping with climate change, ecological environmental protection, and GELC development [23]. Among them, coping with climate change is the main line, ecological environment protection is the foundation for coping with climate change, and GELC development is the principal factor affecting climate and environment. On 12 May 2017, the National Energy Board (NEA) released the Vision and Action for Promoting Energy Cooperation in the Silk Road Economic Belt and the 21st Century Maritime Silk Road [24], stating that energy cooperation needs to adhere to the six basic principles, that is, openness, mutual benefit, market operations, security development, green development and harmonious development, which demonstrates China's firm determination to cooperate with $B \& R$ countries in promoting the global GELC development. At present, China is actively carrying out international cooperation in coping with climate change under the B\&R framework and building a B\&R GELC community, which can provide opportunities for the common development and prosperity of $B \& R$ countries, effectively promote global GELC transformation, and provide a platform for China's deep participation in global governance.

Along the $B \& R$, there are a number of emerging economies with growth potential and vitality, oil exporting countries, and vulnerable areas like small island and the least developed countries, where the population, GDP, energy consumption and carbon emissions account for $2 / 3,1 / 3,50 \%$ and $60 \%$ of the world's total, making the region a more sensitive area for GELC development [25]. As a mirror and banner of global energy governance, B\&R countries are faced with similar climate change problems at the current stage of development, and are seeking for GELC economic development, innovative growth methods for science, technology, energy and industries, so as to reduce the ecological and climate issues brought about by economic development, avoid the lock-in effect of high carbon path and associated development traps, improve the quality of low-carbon investment and employment levels, and share the green benefits brought about by GELC transition. Under the B\&R framework, actively developing international cooperation in dealing with climate change and building 
a B\&R low-carbon community will not only provide opportunities for the common development and prosperity of countries along B\&R, but also effectively promote global GELC transition [26].

Although the international community and various countries have given extensive attention to issues such as climate, environment and GELC development, there is still less concern for the countries along the B\&R. Most countries along B\&R are still in a period of rapid economic development and urbanization. How to effectively improve energy efficiency and achieve GELC targets are major challenges for them. Carbon intensity is an important indicator reflecting the degree of GELC development. Therefore, this paper focuses on some key issues of carbon intensities in B\&R countries, including their spatial distribution and convergence, aiming to grasp the evolution law of the carbon intensity in these countries. Furthermore, by introducing some relevant variables, this paper examines the influencing factors of carbon intensity in B\&R countries and China's contributions to these countries' GELC development, providing data support and theoretical basis for the B\&R countries to formulate corresponding GELC policies.

Traditional econometric techniques are based on the assumption that data is homogeneous [27-30], without considering spatial dimensions [31-33], which is not realistic in investigating carbon intensity issues across countries with geographical differences, resulting in a biased result [34]. Therefore, it is necessary to consider the geospatial carriers when examining the direct influence of explanatory variables, so as to prove the existence of spatial effects of explanatory variables through the spatial conduction mechanism. The uneven economic development and resource endowment of B\&R countries have determined that there are significant regional differences in carbon emissions [35]. In order to achieve the GELC targets, it is necessary to identify the spatial distribution characteristics of carbon intensity and analyze the mechanism and contribution of the main influencing factors in carbon intensity. Therefore, this paper employs spatial panel analysis techniques to examine the evolution and spatial distribution characteristics of carbon intensity in the countries along $B \& R$, and the impact of changes in the main influencing factors on the carbon intensity. The research results in this paper can provide effective scientific basis for the international community and various countries along $B \& R$ to formulate differential carbon emission reduction policies, so as to achieve the GELC development. On the whole, the contributions of this paper include:

(1) This paper uses carbon intensity as an indicator reflecting the degree of GELC development. By analyzing the spatial distribution and spatial convergence of the carbon intensity in 29 B\&R countries, the potential and main influencing factors of GELC development in these countries are identified. In the examination of spatial convergence, this article added two factors named investment rate and openness, which reflect the influence of the B\&R Initiative on the GELC development in countries along the route.

(2) Based on the empirical results and the status of the social, economic and energy development of the B\&R countries, this paper presents several policy recommendations for the GELC development under the $B \& R$ framework, including the contributions China should make as an advocate, the national efforts of the B\&R countries should make, and the goals that China and the $B \& R$ countries should achieve together. The proposals make full use of the international cooperation platform provided by the B\&R Initiative, which can promote the GELC development in these countries and further promote the global GELC targets.

The rest of this paper is organized as follows: Section 2 explains the basic situations of B\&R countries and factors influencing the carbon intensity of B\&R countries. Section 3 displays the spatial distribution of carbon intensity across B\&R countries. Section 4 introduces the spatial convergence model based on spatial panel econometric techniques. Section 5 reports the empirical findings about the convergence of carbon intensity across $B \& R$ countries and the final section summarizes this paper and puts forward several suggestions on GELC development according to the empirical findings. 


\section{The Basic Situations of B\&R Countries and the Influencing Factors of Carbon Intensity}

\subsection{Basic Situations of BER Countries}

The countries along the B\&R are rich in energy resources [36]. For example, the reserves of oil, gas and coal in these countries account for $58.7 \%, 79.4 \%$ and $50.1 \%$ of the world's total reserves respectively. However, the energy production in these countries accounts for less than $40 \%$ of the world's total, and the energy consumption accounts for less than $30 \%$, as showed in Figure 2. Economic developments in most B\&R countries are still depended on huge energy consumption. The energy consumption is much lower than the energy output, indicating that energy has not been fully utilized for export or storage, or that the energy demand is saturated at the current economic and technological level, so the industrial structure and energy utilization technologies require transformation and upgrading. China has good development experience in the transformation and upgrading of the energy industry and the use of technology, which can help those countries to break the bottleneck of energy development and reach a green energy path [37].

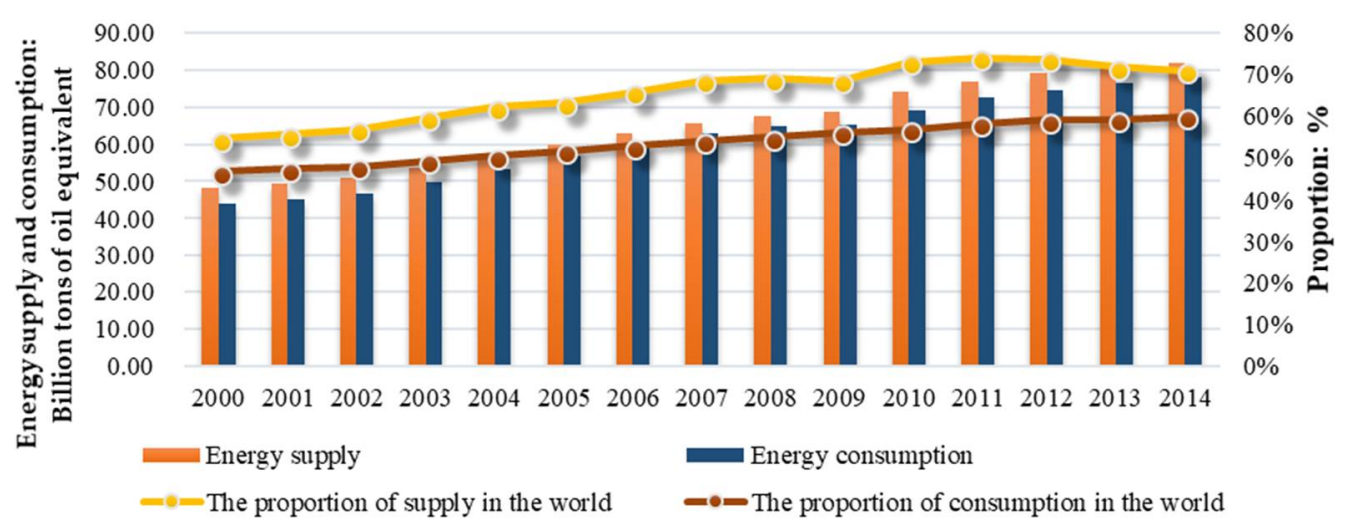

Figure 2. The total energy production and consumption of B\&R countries from 2000 to 2014.

According to Figure 3 which shows the relationship between per capita GDP and per capita energy consumption in 27 major countries and regions in 2013, and to Figure 4 which represents the relationship between per capita GDP and per capita carbon emissions in those countries and regions in 2013, there are three economic development modes for major international powers: the US-Canadian mode (high energy consumption, high carbon emissions and high GDP, H-H-H), the EU-Japan mode (low energy consumption, low carbon emissions and high GDP, L-L-H), and the China-Russia mode (high energy consumption, high carbon emissions and low GDP, H-H-L). In addition, there are many countries that fall between the US-Canada mode and the China-Russian mode, whose overall distribution is concentrated in areas with low energy consumption, low carbon emissions and low GDP. Most B\&R countries are still in a vicious cycle of relying on high energy consumption to drive GDP [38], belonging to the China-Russia mode of $\mathrm{H}-\mathrm{H}-\mathrm{L}$, which is not in line with the GELC development trend. B\&R countries are at a critical stage of rapid economic development. Their future economic development modes should aim at the EU-Japan mode rather than the China-Russia mode, revealing that they should devote themselves to GELC development. Despite many setbacks, China has obtained rich and successful experiences in developing a GELC economy. In recent years, China is also committed to sharing these successful experiences with B\&R countries via the B\&R framework [39,40], aiming to promote the GELC development in these countries.

In the global economic downturn and weak recovery, global trade has shrunk and trade protectionism has risen. In 2016, the Britain decided to exit from the EU, and in early 2017, US President Trump has announced that the United States will withdraw from the Trans-Pacific Partnership Agreement (TPP) and subsequently issued a series of protectionist policies, showing that the wave of "reverse globalization" is gradually warming up [41,42]. At the same time, Chinese President Xi 
Jinping said at the Boao Asian Economic Forum in 2017 that China will continue to adhere to the policy of reform and opening up, making the smooth flow of trade as a key component of the B\&R Initiative to strengthen trade and economic cooperation with B\&R countries [43]. Under the global economic downturn and the rise of trade protectionism, China's trade with $B \& R$ continues is growing rapidly and has great potential. Expanding trade cooperation has important implications for stabilizing $B \& R$ countries' economic growth and promoting regional economic integration [44]. As showed in Figure 5, China occupies an important position in the trade activities of B\&R countries and is their main trading partner. Owing to technological capabilities, industrial energy consumption in countries along the route is mostly at a relatively high level. Thus, actively introducing low-energy equipment from China has a significant contribution to the entire country in terms of GELC development.

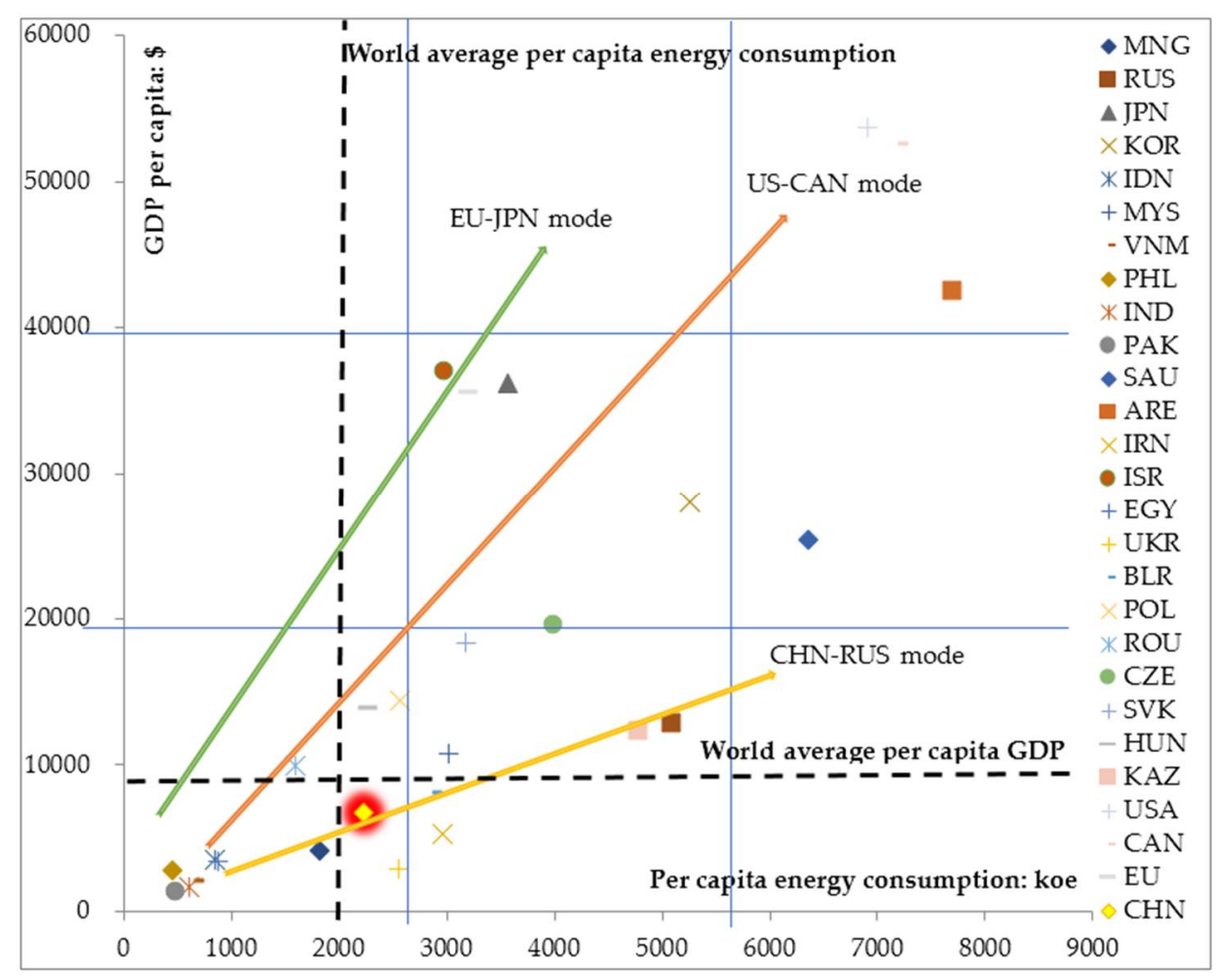

Figure 3. Per capita GDP and per capita energy consumption in 27 major countries in 2013. Note: koe means $\mathrm{kg}$ oil equivalent.

Many developing countries along B\&R have relatively poor infrastructure conditions. In the opening and development of these countries, the bottleneck effect caused by the inadequate infrastructure on economic development has gradually emerged [45]. China's technologies and production capacity in green energy utilization have reached the world's advanced level, and the promotion of cooperation in infrastructure projects is highly consistent with the needs of $B \& R$ countries, so the field of infrastructure construction is the easiest to reach consensus in cooperation and developed rapidly in recent years. In 2016, China's foreign contracted engineering business achieved a total turnover of 159.4 billion dollars, with an increase of $3.5 \%$, of which the contracted projects in B\&R countries completed a turnover of 76 billion dollars, accounting for $47.7 \%$ of the total. Among the top 10 projects contracting countries, Asian and African ones have nine seats, including five B\&R countries. China has strong competitiveness in the construction of highway bridges and medium- and high-end manufacturing industries such as high-speed rail, nuclear power, UHV power transmission and transformation, and smart grids. Therefore, China's overseas contracting projects are mainly concentrated in fields such as electricity, transportation and general housing construction. The international production capacity cooperation projects such as the Yawon High-speed Rail and the 
Kezim Port coal-fired power station have been successfully implemented, supporting the fact that the markets of $B \& R$ countries can provide new opportunities for the development of Chinese companies and Chinese companies can promote the GELC development in the B\&R countries in turn.

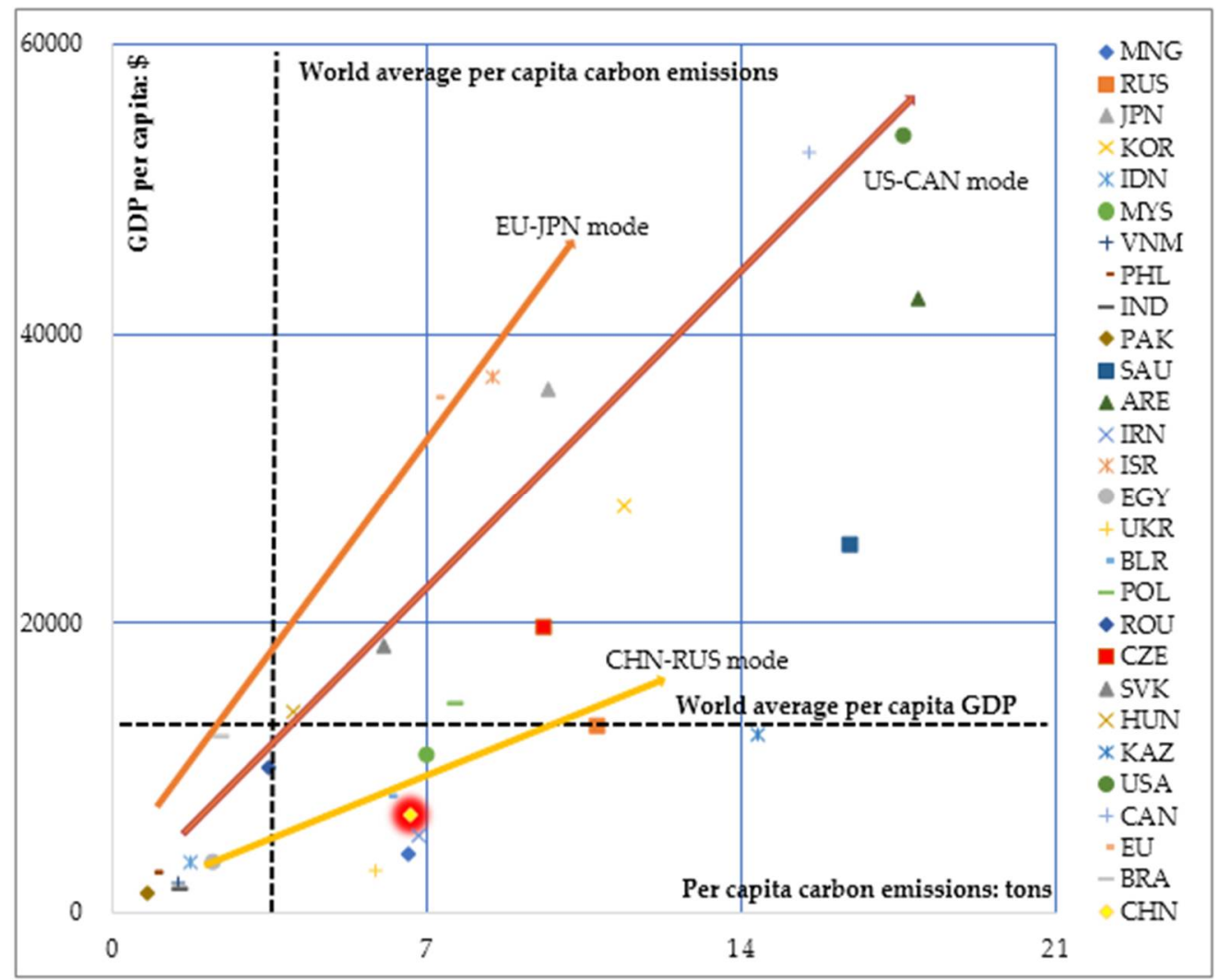

Figure 4. Per capita GDP and per capita carbon emissions in 27 major countries in 2013.

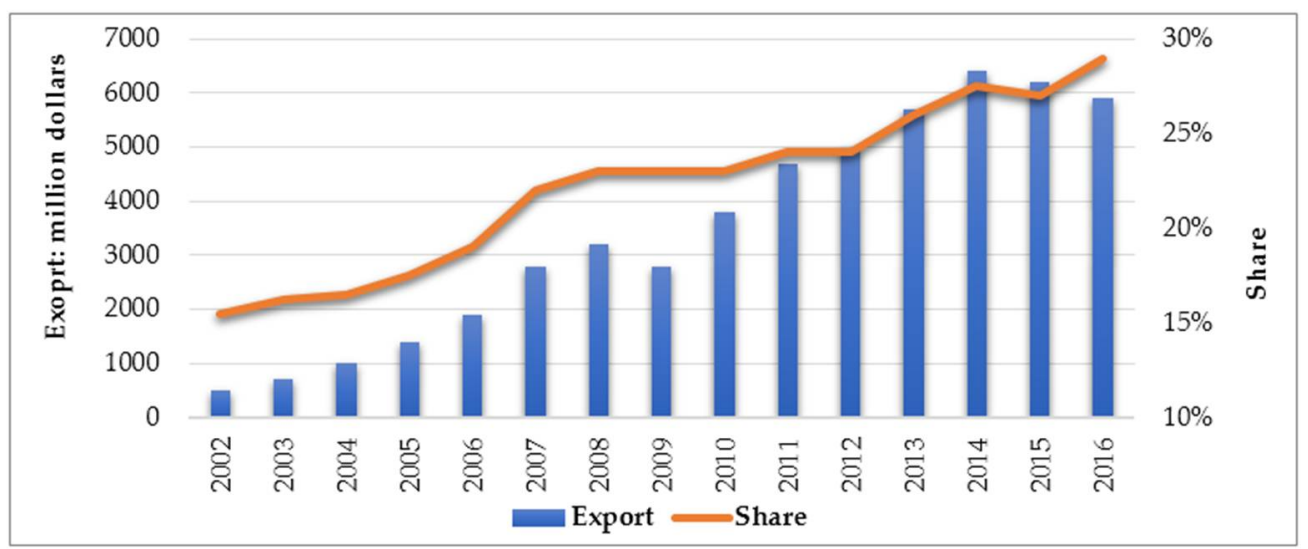

Figure 5. China's exports to the B\&R countries and the share of China's total exports.

As an important initiative for international regional economic cooperation, the B\&R Initiative has incorporated the development of a GELC economy into the focus of cooperation. According to the World Bank, during the period 1995-2012, the B\&R countries experienced an average annual increase of economic growth, energy input and carbon emissions of $6.04 \%, 3.67 \%$ and $3.16 \%$, far higher than those of the world average. In 1995, the total economic output, aggregate energy input and total carbon emissions of the B\&R countries accounted for $15.06 \%, 35.5 \%$ and $38.45 \%$ of the world's total. By 2012, these three ratios rose to $24.68 \%, 45.5 \%$ and $45.97 \%$ respectively. A series of data shows that the B\&R 
national economy has the characteristics of "high growth, high energy consumption and high carbon emissions", which is difficult to sustain. Therefore, it is necessary for all countries to take into account both the input of resources and the carrying capacity of the environment when achieving coordinated economic development. However, a realistic difficulty for B\&R countries is to solve the environmental problems without hindering the economic development, that is, to achieve the GELC economic growth, which is what the B\&R Initiative can contribute to.

\subsection{Influencing Factors of Carbon Intensity in BER Countries}

In order to more effectively examine the relationship between economic growth and environmental pollution, the academic community introduced indicators such as per capita carbon emissions, carbon intensity and carbon emission efficiency into the framework [46-48]. Among them, carbon intensity refers to the carbon emissions produced per unit of economic output, including the carbon emissions per unit of GDP or carbon emissions per unit of per capita GDP, which reflects the efficiency of energy use in the region [49]. Besides, carbon intensity can reflect the degree of GELC development in the region. The small carbon intensity indicates the high energy efficiency, which is conducive to encouraging countries to improve energy efficiency and promoting the development of low-carbon industries and green energy. At present, the international community tends to utilize carbon intensity as an emission reduction standard. The carbon intensity reflects economic growth and carbon emissions, which is in line with the idea of GELC development. At the same time, carbon intensity can effectively reflect the level of economic development, technological progress and energy efficiency of a country or region and is an important indicator of environmental quality [50]. There are large differences in the level of development among $B \& R$ countries and achieving carbon reduction targets requires that $B \& R$ countries achieve remarkable results in energy conservation and emission reductions in multiple areas and at various levels. However, the contradictions between economic development and carbon reduction in different countries have distinct characteristics. Therefore, it is necessary to have a deep understanding of the main influencing factors of carbon intensity, to quantify the impact effects and their degrees, and to assess the contributions of various factors to carbon intensity in different B\&R countries, which can help to find out the key factors that promote or inhibit carbon emissions and provide scientific basis for B\&R countries to formulate GELC policies according to local conditions. According to the basic situations of $B \& R$ countries and some previous researches [50-52], the influencing factors of carbon intensity in B\&R countries include:

(1) Influence of population on carbon emissions. The total population of B\&R countries (excluding China) accounted for $46.3 \%$ of the world's population. The increasing population means the increasing demand for energy, transportation and necessities of life, which may consume lots of primary energy, especially fossil fuels, thereby increasing carbon dioxide emissions. In addition, human activities will increase the degree of damage to forest lands and objectively increase $\mathrm{CO}_{2}$ emissions. Therefore, the $\mathrm{CO}_{2}$ emissions from population growth will still maintain a certain scale.

(2) Impact of economic growth on carbon emissions. At present, most B\&R countries are in the early stage of industrialization, and some are in the mid-term. The economic growth makes the demand for energy, raw materials and transportation more pressured. For a long time in the future, energy-intensive industries are still the basic industry in most B\&R countries. With the remarkable advancement of industrialization in these countries, the demand for energy-intensive products from large-scale infrastructure construction is also increasing, which produces more carbon emissions. From the development history of developed countries, the relationship between economic development and carbon emission in industrialized countries generally require three inverted U-shaped curves of carbon intensity, per capita carbon emissions and total carbon emissions [53-55]. When a country is in the climb phase of inverted U-shaped curve, economic growth inevitably leads to an increase in carbon emissions. Otherwise, the country will emerge out of this dilemma, and economic growth will reduce carbon emissions. Figure $7 \mathrm{a}-\mathrm{c}$ show the 
relationships between per capita emissions and per capita GDP in the three typical B\&R countries named Singapore, China and India from 1980 to 2014, showing that per capita carbon emissions in Singapore are already on the right side of an inverted U-shaped curve, and those in China and India witnessed a decrease in 2014.

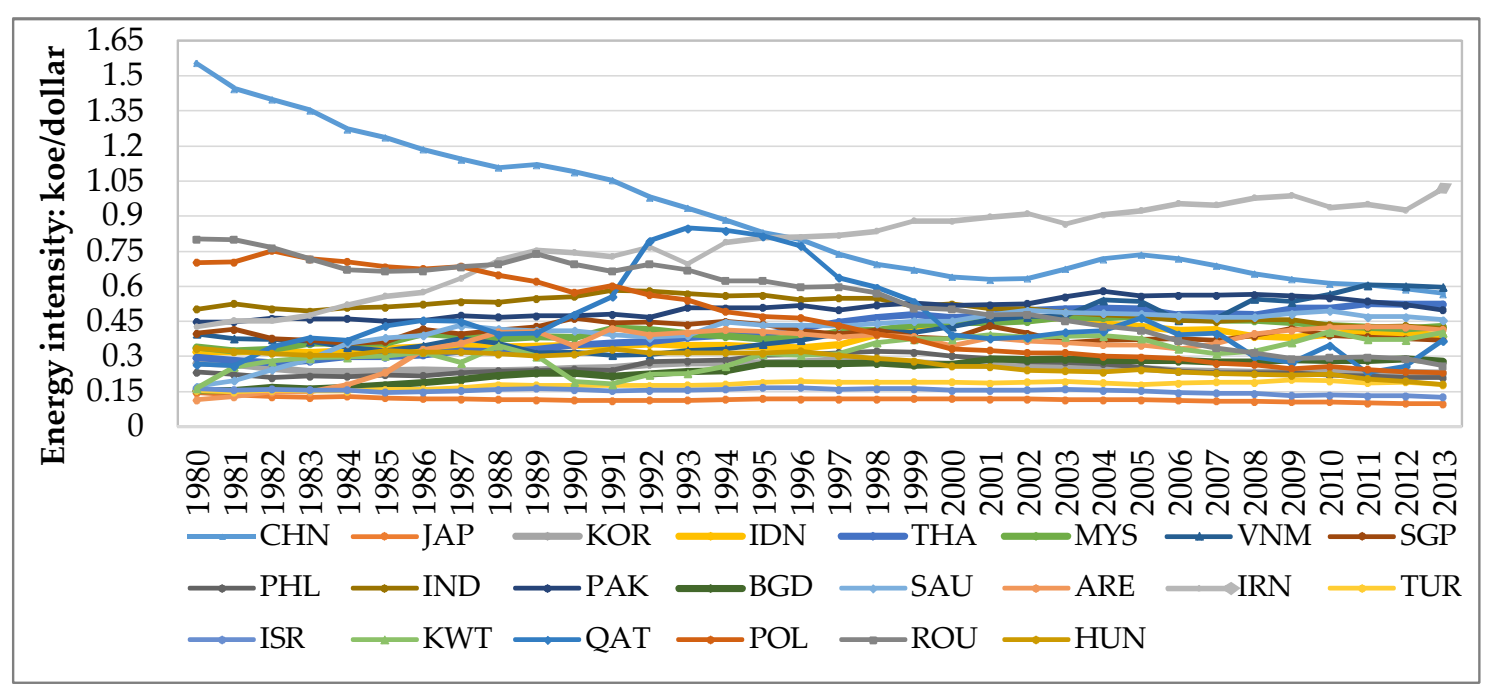

Figure 6. Energy intensities in 22 major B\&R countries during 1980-2013.

(3) Impact of energy intensity on carbon emissions. Energy intensity is part of the most important indicators to measure the efficiency of energy use in a country or region, reflecting the dependence of the economy on energy, mainly in terms of economic structure, economic system, technological level and energy structure. The changes in energy intensity can be divided into economic structural changes and energy efficiency changes [56]. The decline in energy intensity may be due to a decline in the proportion of energy-intensive industries, or the reduction in energy consumption of the same unit of production. The former is called structural economic changed and the latter is the change in energy efficiency. As showed in Figure 6, most of the B\&R countries are developing countries having a large demand for energy and relatively high energy intensities. The GELC economic development and scarcity of energy make it an important issue for countries to improve the efficiency of energy use and reduce the energy consumption per unit of output.

(4) Impact of energy carbon intensity on carbon emissions. Energy carbon intensity refers to the amount of $\mathrm{CO}_{2}$ emitted by a unit of primary energy consumption. Since the $\mathrm{CO}_{2}$ emission coefficients of the three fossil fuels, coal, natural gas and oil, are different, and green energy does not emit $\mathrm{CO}_{2}$, the energy carbon intensity is an indicator reflecting the degree of cleanliness (or optimization) of the energy consumption structure [57]. The serious environmental pollution problems that have arisen in the energy consumption process have become rigid constraints that hinder the sustainable development of human society and economy. Therefore, it is imperative to reduce the single energy structure based on coal resources, and actively develop green energy such as hydropower, nuclear power and solar energy, which is conducive to reducing carbon emission levels and thereby promoting the coordinated and sustainable development of energy and environment, that is, the GELC development. 


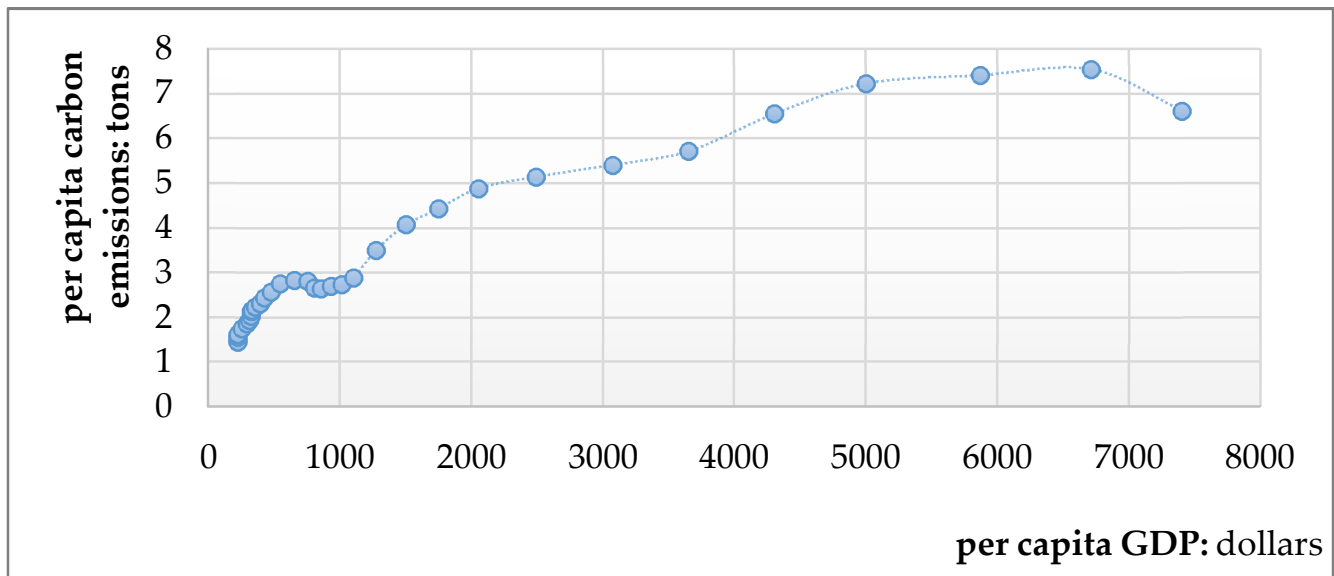

(a)

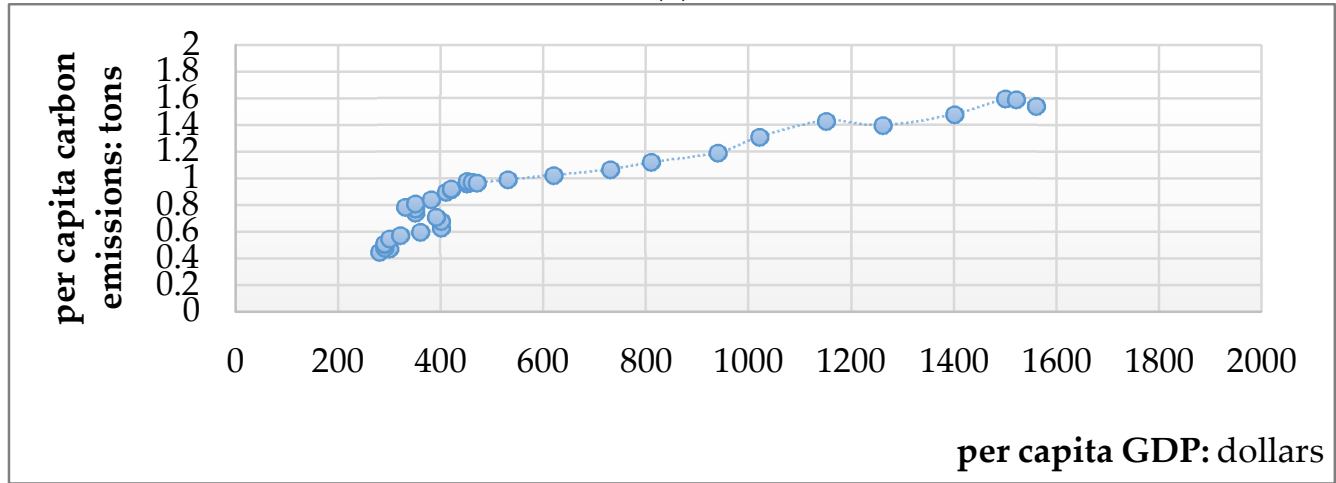

(b)

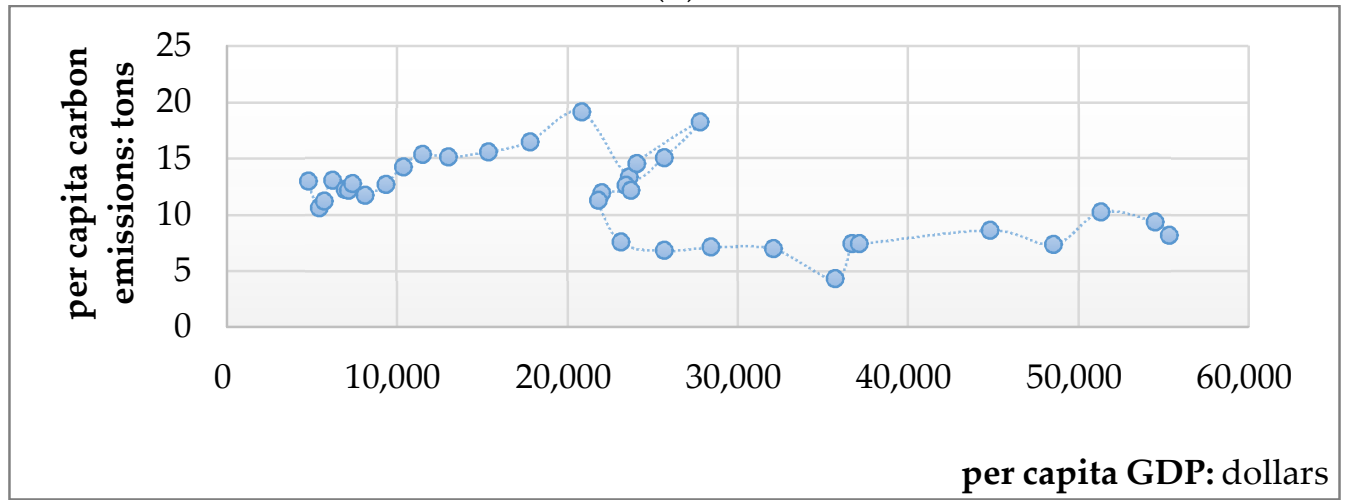

(c)

Figure 7. The relationships between per capita emissions and per capita GDP in three typical B\&R countries. (a) is the relationship in Singapore; (b) represents that in China and (c) is that in India.

\section{Spatial Correlation and Distribution of Carbon Intensity in 29 B\&R Countries}

\subsection{Spatial Correlation Test Approaches}

Spatial correlation is a measure of the degree of data aggregation in space and is also a prerequisite for the construction of a spatial econometric model. To examine the spatial correlation of the carbon intensity in the B\&R countries is to analyze the spatial distribution of carbon intensity in these countries. The Exploratory Spatial Data Analysis (ESDA) method is mainly used to test the spatial autocorrelation of distribution, combining statistics with modern graphic computing techniques to intuitively display the spatial distribution, spatial patterns, and spatial interactions implicit in spatial data [58]. This method is the data-driven research process rather than the theory-driven deductive 
reasoning, which can achieve the purpose of letting the data speak for itself. ESDA mainly uses two kinds of analysis tools named global spatial correlation test using Moran's I to analyze the distribution characteristics of spatial data in the entire system, and local spatial correlation test using local Moran's I and Moran scatterplot to reflect the spatial agglomeration areas, spatial politic areas, and atypical local areas. In this section, the global Moran's I, the local Moran's I and the Moran's scatterplot are adopted to explore the agglomeration and radiation effects of carbon intensity in 29 B\&R countries, considering the availability of relevant data. For the convenience of subsequent descriptions, the acronyms of the examined $29 \mathrm{~B} \& \mathrm{R}$ countries are listed in Table 1.

Table 1. Acronyms of the 29 examined B\&R countries.

\begin{tabular}{cccccc}
\hline Country & Acronym & Country & Acronym & Country & Acronym \\
\hline United Arab & ARE & Romania & ROU & Singapore & SGP \\
Emirates & KAZ & Slovakia & SVK & Pakistan & PAK \\
Kazakhstan & EGY & Hungary & HUN & Turkey & TUR \\
Egypt & JPN & Turkmenistan & TKM & Ukraine & UKR \\
Japan & IDN & Vietnam & VNM & Poland & POL \\
Indonesia & MYS & Bangladesh & BGD & Czech Republic & CZE \\
Malaysia & PHL & Saudi Arabia & SAU & Bulgaria & BGR \\
Philippines & IRN & Russia & RUS & Uzbekistan & UZB \\
Iran & ISR & Republic of Korea & KOR & India & IND \\
Israel & BLR & Thailand & THA & - & - \\
Belarus & & & & &
\end{tabular}

\subsubsection{Global Spatial Correlation Test}

The global Moran's I is commonly used to test global spatial correlation. According to the global Moran's I, it can be judged whether the adjacent regions in the entire study interval are spatially positively correlated, spatially negatively correlated, or independent. The global Moran's I can be estimated according to the following equation [59]:

$$
\text { Moran's } I=\frac{N \sum_{i} \sum_{j} w_{i j}\left(x_{i}-\bar{x}\right)\left(x_{j}-\bar{x}\right)}{\left(\sum_{i} \sum_{j} w_{i j}\right) \sum_{i}\left(x_{i}-\bar{x}\right)^{2}}=\frac{\sum_{i} \sum_{j \neq i} w_{i j}\left(x_{i}-\bar{x}\right)\left(x_{j}-\bar{x}\right)}{S^{2} \sum_{i} \sum_{j} w_{i j}}
$$

where $N$ presents the numbers of regions in the entire study interval, $w_{i, j}$ is an element in the spatial weight matrix $W$ set up using the $0-1$ adjacency matrix method, $x_{i}$ and $x_{j}$ represent the observed values of the regions $i$ and $j, \bar{x}$ is the mean of the observed values and $\bar{x}=\frac{1}{N} \sum_{i=1}^{N} x_{i}$, and $S^{2}$ is the variance of observed values and $S^{2}=\frac{1}{N} \sum_{i=1}^{N}\left(x_{i}-\bar{x}\right)^{2}$. The global Moran's $I$ can be considered as the correlation coefficient between the observed value and its spatial lag item, indicating that the spatial lag item of the variable $x_{i}$ is its average value in the neighborhood, which can be expressed as follows:

$$
x_{i,-1}=\sum_{j} w_{i j} x_{i j} / \sum_{j} w_{i j}
$$

Therefore, the range of Moran's $I$ is $[-1,1]$. If the value of Moran's $I$ is significantly greater than 0 , it indicates that the variables studied are positively correlated and there is an agglomeration effect. When the Moran index is close to 1 , it indicates that similar attributes cluster together (high-high adjacent and low-low adjacent). If the value of Moran's I is significantly less than 0 , it means that the variables studied are negatively correlated and have diffusion effects. When the value is close to -1 , it reveals that different attributes cluster together (high-low adjacent and low-high adjacent). If the value of Moran's $I$ is significantly close to 0 , it means that the variables are spatially independent and there is no spatial autocorrelation. In addition, the absolute value of the global Moran's I can reflect the degree of spatial correlation. The greater the absolute value, the greater the spatial correlation. 
The significance of spatial correlation needs to be judged by "discarding false truth" in statistical theory. In general, the significance of the Moran's I under the assumption of the normal distribution is tested by the $Z$ statistic, which is shown in the following equation [59]:

$$
Z=\frac{\text { Moran's } I-E(I)_{\sqrt{\operatorname{Var}(I)}}}{\sqrt{2}}
$$

where $E(I)=-1 /(N-1), \operatorname{Var}(I)=\frac{N^{2} w_{1}+N w_{2}+3 w_{0}}{w_{0}^{2}\left(N^{2}-1\right)}-E^{2}(I), w_{0}=\sum_{i} \sum_{j} w_{i j}, w_{1}=\frac{1}{2} \sum_{i} \sum_{j}\left(\left(w_{i j}+w_{j i}\right)^{2}\right.$, $w_{2}=\sum_{i}\left(w_{i}+w_{j}\right)^{2}$. Among them, $w_{i}$ and $w_{j}$ represent the sums of the $i$-th raw and the $j$-th column of the spatial weight matrix. Under the assumption of normal distribution, the null hypothesis is that there is no spatial correlation among the variables, that is, the distribution of the regional data and the distribution of the value of the regional position are independent of each other. If the estimated $p$-value of the $Z$ statistic can pass the 5\% (or 10\%) significance level test, the null hypothesis is rejected and the regional data is considered relevant. Furthermore, when the $Z$ statistic is greater than 0 , there is a spatially positive correlation between the attribute values of the region data, meaning that similar observations tend to spatially gather, when the $Z$ statistic is less than 0 , there is a negative spatial correlation, revealing that similar observations tend to be spatially dispersed, and when the $Z$ statistic is equal to 0 , the observations are independent and random.

\subsubsection{Local Spatial Correlation Test}

The global Moran's I can only describe the spatial distribution of carbon intensity in the B\&R countries from the overall scope, which may average the differences between regions, and thus cannot specifically reflect whether regional units have regional agglomeration [60]. The spatial distribution of local regions may show special circumstances that global indicators cannot reflect. Therefore, in order to further study the agglomeration of local space, a local spatial correlation test is needed. Therefore, in order to further study the agglomeration of local space, a local spatial correlation test is needed. Local spatial autocorrelation is used to reflect whether there is similarity between the same attribute values between each region and the surrounding region, which can test whether the local region has spatial heterogeneity, thus making up for the lack of global spatial autocorrelation [60]. Normally, the local Moran's I is adopted to examine the local spatial correlation among different regions, which can analyze the agglomeration degree and type of each region. The local Moran's I can be expressed as below [59]:

$$
\text { Local Moran's } I=\frac{\left(x_{i}-\bar{x}\right) \sum_{j} w_{i j}\left(x_{j}-\bar{x}\right)}{S^{2}}
$$

If the local Moran's I greater than 0 , it means that the observation value in the region is similar to that in the neighboring region, that is, a high-high adjacent or a low-low adjacent. If the local Moran's $I$ is less than 0 , it reveals that the observation value in the region is different from that in the neighboring region, indicating a high-low adjacent or a low-high adjacent. Similar to the global Moran's I, the significance level of local Moran's I is tested using Z statistic obtained by Equation (3).

Apart from local Moran's I, the Moran scatter plot proposed by Anselin [61] is also widely adopted to analyze the internal structure of the global space and the correlation between local spaces. The Moran scatter plot takes $(z, W z)$ as the coordinate point (the abscissa is the deviation $z$ of the observations in each region, and the ordinate is the spatial lag $W z$ ), that is, Moran scatter plot is a two-dimensional illustration of the spatial lag factors $z$ and $W z$, where $z_{i}=x_{i}-\bar{x}$ is the spatial lag factor, $W$ is the spatial weight matrix, and $W z$ is the spatial weighting of the observations. The four quadrants of the Moran scatter plot correspond to the four types of local spatial associations [62]: The first quadrant is a HH-typed agglomeration (high carbon intensity and high spatial lag), showing that regions with high observations are surrounded by neighboring regions with high values. The second quadrant is 
a LH-typed agglomeration (low carbon intensity and high spatial lag), revealing that regions with low observations are surrounded by neighboring regions with high values. The third quadrant is a LL-typed agglomeration (low carbon intensity and low spatial lag), indicating that regions with low observations are surrounded by neighboring regions with low values. The fourth quadrant is a HL-typed agglomeration (high carbon intensity and low spatial lag), showing that regions with high observations are surrounded by neighboring regions with low values. Among them, the first and the third quadrant represent positive spatial correlations, while the second and the fourth quadrant represent negative spatial correlations.

\subsection{The Spatial Distribution of the Carbon Intensity in 27 BER Countries}

\subsubsection{Global Spatial Distribution: Agglomeration Effect}

The global Moran's I values of the carbon intensity in B\&R countries over the period 1995-2014 are calculated according to Equation (1), as shown in Table 2. It can be seen that the global Moran's I value in each year is significantly greater than 0 , showing a positive spatial correlation of the carbon intensities in different countries. The results supports a positive spatial correlation of HH-typed aggregation and LL-typed aggregation of carbon intensity in the B\&R countries, that is, countries with high carbon intensities tend to be close to other countries with high carbon intensities, and countries with low carbon intensities tend to be close to other countries with low carbon intensities, indicating that the national carbon intensities of the $B \& R$ countries are spatially related and cannot be assumed to be an independent observation. In view of this, when exploring the influencing factors and convergence of carbon intensity in the countries along the $B \& R$, it is necessary to consider the spatial agglomeration and spillover effects between different countries.

Table 2. Global Moran's I of the carbon intensity in 29 B\&R countries during 1995-2014.

\begin{tabular}{|c|c|c|c|}
\hline Year & Global Moran's I & Z-Statistic & $p$-Value \\
\hline 1995 & 0.440 & 2.845 & $0.002 * * *$ \\
\hline 1996 & 0.401 & 2.595 & $0.005^{* * *}$ \\
\hline 1997 & 0.379 & 2.469 & $0.007^{* * *}$ \\
\hline 1998 & 0.289 & 1.938 & $0.026^{* *}$ \\
\hline 1999 & 0.367 & 2.404 & $0.008^{* * *}$ \\
\hline 2000 & 0.357 & 2.348 & $0.009^{* * *}$ \\
\hline 2001 & 0.367 & 2.406 & $0.008^{* * *}$ \\
\hline 2002 & 0.358 & 2.347 & $0.009^{* * *}$ \\
\hline 2003 & 0.318 & 2.113 & $0.017^{* *}$ \\
\hline 2004 & 0.257 & 1.752 & $0.040^{* *}$ \\
\hline 2005 & 0.241 & 1.649 & $0.050 *$ \\
\hline 2006 & 0.241 & 1.653 & $0.049^{* *}$ \\
\hline 2007 & 0.184 & 1.547 & $0.061 *$ \\
\hline 2008 & 0.179 & 1.493 & $0.068 *$ \\
\hline 2009 & 0.195 & 1.466 & $0.071 *$ \\
\hline 2010 & 0.182 & 1.545 & $0.061 *$ \\
\hline 2011 & 0.113 & 1.388 & $0.083 *$ \\
\hline 2012 & 0.103 & 1.355 & $0.088 *$ \\
\hline 2013 & 0.093 & 1.341 & $0.090 *$ \\
\hline 2014 & 0.108 & 1.361 & $0.087 *$ \\
\hline
\end{tabular}

Figure 8 reports the trends of global Moran's I, showing that the global Moran's I generally shows a downward trend and can be roughly divided into five phases: (1) From 1995 to 1998, the global Moran's I continued to decline from 0.44 in 1995 to 0.289 in 1998, indicating that the spatial correlation of carbon intensity in the 29 B\&R countries has continued to weaken; (2) From 1999 to 2002, the global Moran's I remained at around 0.36, showing a strong spatial correlation between the national carbon 
intensity of the B\&R countries; (3) From 2003 to 2006, the global Moran's I fell further to around 0.25 , indicating that the spatial correlation of carbon intensity in the examined countries has further weakened; (4) In 2007-2010, the global Moran's I remained at around 0.2, showing a weak spatial correlation of carbon intensity in the countries continues; (5) In 2011-2014, the global Moran's I dropped to around 0.1 , indicating that the carbon intensity of the B\&R countries is less spatially related. The existence of spatial correlation indicates that the carbon intensity of a country is not only related to its own situation, but also affected by factors such as resources and environment of neighboring countries. The technological level and international trade make the spatial correlation of economic development, energy consumption and carbon intensity of the B\&R countries more strengthened. Therefore, it is more appropriate to choose the spatial econometric model to analyze the influence of different factors on the convergence of carbon intensity in the B\&R countries.

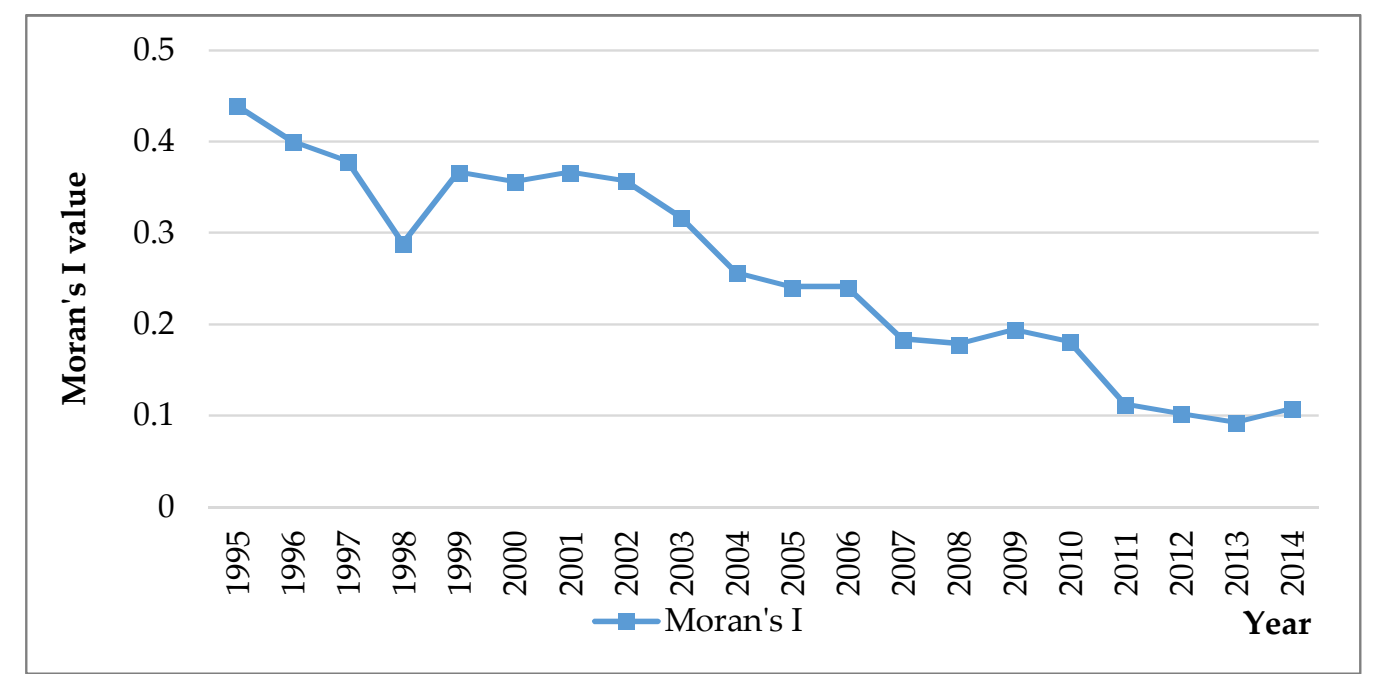

Figure 8. The trends of global Moran's I during 1995-2014.

\subsubsection{Local Spatial Distribution: Radiation Effect}

Although the global Moran's I shows that there is a spatially positive correlation between the carbon intensity of the analyzed $B \& R$ countries, it may mask the specificity of local areas, that is, it cannot display in detail the type of agglomeration of carbon intensity in every country. Therefore, the local autocorrelation test is a necessary link reflecting the radiation effect of a country's carbon intensity on the surrounding areas. In this section, the local Moran's I and Moran scatter plots are employed to examine the local spatial distribution of carbon intensities in B\&R countries.

In line with the above discussion, there are six key time nodes in the spatial agglomeration effect of the carbon intensity of B\&R countries, that is, 1995, 1998, 2002, 2006, 2010 and 2014, according to Figure 8. Hence, the Moran scatter plots for the above six time points are drown to reflect the local spatial distribution of B\&R countries' carbon intensity (Figure 9). In the Moran scatter plot, the first and third quadrants mean that countries with the same level of carbon intensities border each other, and the second and fourth quadrants indicate that countries with different levels of carbon intensities are adjacent. As shown in Figure 9, from 1995 to 2014, the spatial agglomeration type of carbon intensity in the examined $B \& R$ countries is constantly changing.

In order to learn more clearly the distribution of carbon intensity in every country in space, the countries in different quadrants of Moran scatter plot are listed in Table 3, from which it can be seen that in 1995, carbon intensity in most countries belongs to HH or LL type, revealing that the carbon intensity has a significant agglomeration distribution characteristic across countries. But then, some countries transferred to other types like HL and LH. Specifically, (1) For HH type, there were 10 countries in 1995, nine in 1998 and eight eventually, of which KAZ, IRN, BLR, TKM, RUS, AND, UZB are located in HH 
quadrant all the time. BGR withdrew from the HH type in 1998, POL withdrew in 2002, ROU and UKR withdrew in 2006 while THA and PAK joined simultaneously. Overall, the number of HH-type countries dropped from 10 in 1995 to eight in 2014, indicating that the original B\&R countries with high carbon intensity gradually shifted to the low carbon intensity type; (2) For LL type, there were 10 countries in 1995, 7 in 1998, eight in 2002, six in 2006 and seven eventually, of which JPN and KOR are located in LL quadrant all the time. IDN, VNM and SGP withdrew from the HH type in 1998, PHL and SAU withdrew and IDN, SGP and CZE joined in 2002, EGY, MYS and THA withdrew and SVK joined in 2006, HUN joined in 2010, and SGP withdrew and ROU joined in 2014. Overall, the number of LL-type countries dropped from 10 in 1995 to seven in 2014, indicating that some B\&R countries with low carbon intensities deteriorated to high carbon intensity countries; (3) For HL type, there were two countries in 1995, five in 1998, four in 2002 and seven eventually, of which IND is located in HL quadrant all the time. IDN, VNM and BGR joined the HL type in 1998, IDN and CZE withdrew and SAU joined in 2002, and KAZ, MYS and UKR joined in 2006; (4) For LH type, there were seven countries in 1995, eight in 1998, nine in 2002, eight in 2006 and seven in 2010 and 2014, of which ARE, ISR, BGD and TUR are located in HL quadrant all the time. SGP joined the LH type in 1998 but withdrew in 2002, PHL and POL joined in 2002, SVK and PAK withdrew while ROU joined in 2006, HUN withdrew in 2010, and ROU withdrew while SGP joined in 2014.

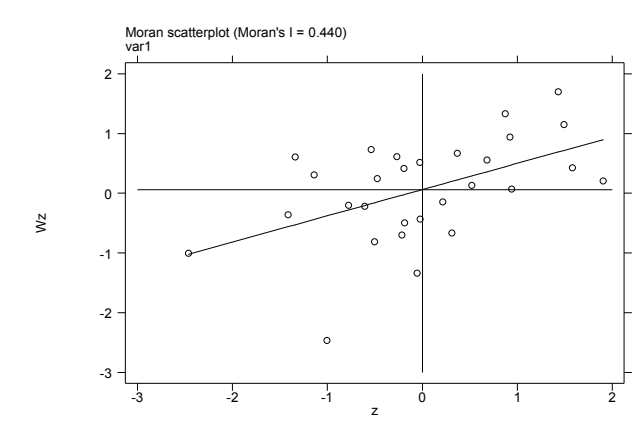

(a)

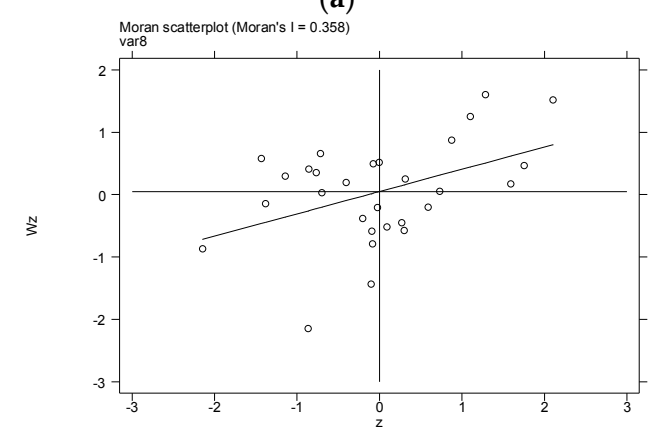

(c)

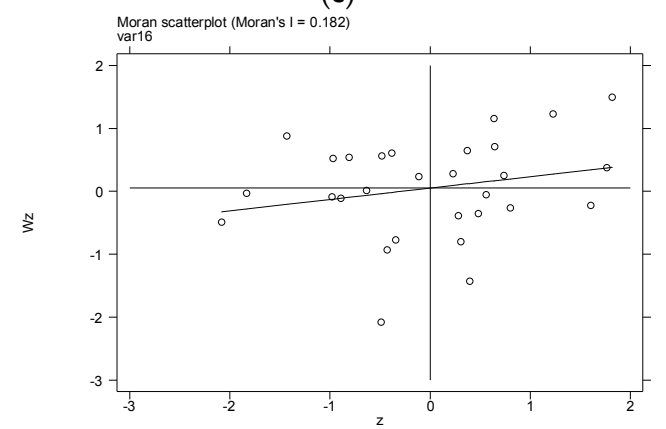

(e)

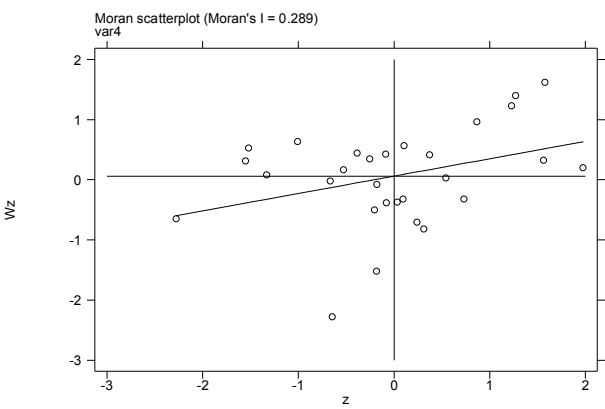

(b)

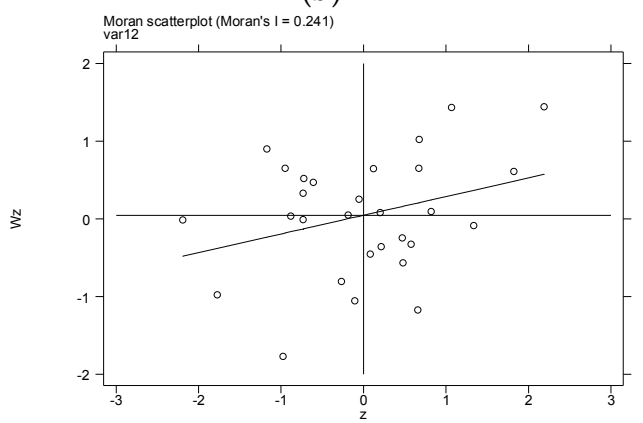

(d)

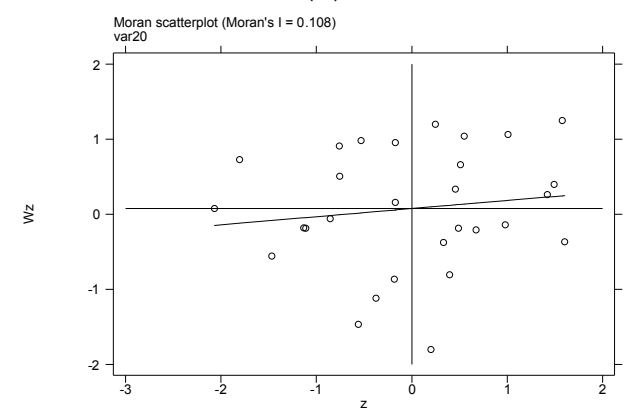

(f)

Figure 9. Moran scatter plots of B\&R countries' carbon intensity in different key time points. Notes: Sub-Figure (a) is the Moran scatter plot of B\&R countries' carbon intensity in 1995; (b) is that in 1998, (c) is that in 2002; (d) is that in 2006; (e) is that in 2010 and (f) is that in 2014. 
Further, the local Moran's I of the carbon intensity of each B\&R country in the six time points is obtained according to Equation (4), which reflects the radiation effect of carbon intensity in each country on that in its surrounding countries. As mentioned before, that the local Moran's $I$ is greater than 0 reveals that the carbon intensity in the area is similar to that in its surrounding areas, that is, there is a HH or LL agglomeration in area. Otherwise, the area is HL or LH type. The spatial agglomeration exists only when local Moran's $I$ is greater than 0 , that is, a HH or LL type. Thus, this paper only explores the countries with local Moran's I values that are greater than 0 , and tests the significance level applying Z-statistics calculated by Equation (3). If the country belongs to the $\mathrm{HH}$ type and passes the significance test, it indicates that the carbon intensity in the country has a large positive driving effect on that in the surrounding areas. If the country is significantly the LL type, it means that the area has a large negative effect on the surrounding areas.

The countries passing the significance test and their local Moran's I values are reported in Table 4, from which several conclusions can be drawn: (1) At the six time points, there are several key countries having significant effects on the surrounding areas, positively or negatively, showing that special attentions should be paid to these countries, which can help to promote the cooperation among $B \& R$ countries to reduce the carbon intensity and achieve a GELC development.

Table 3. Countries in different quadrants of Moran's scatter plots in each time point.

\begin{tabular}{|c|c|c|c|c|}
\hline \multirow{2}{*}{ Time Point } & \multicolumn{4}{|c|}{ Agglomeration Type } \\
\hline & HH Agglomeration & LL Agglomeration & HL Agglomeration & LH Agglomeration \\
\hline 1995 & $\begin{array}{l}\text { KAZ, IRN, BLR, ROU, TKM, } \\
\text { RUS, UKR, POL, GR, UZB }\end{array}$ & $\begin{array}{l}\text { EGY, JPN, IDN, MYS, PHL, } \\
\text { VNM, SAU, KOR, THA, GP }\end{array}$ & CZE, IND & $\begin{array}{l}\text { ARE, ISR, SVK, HUN, BGD, } \\
\text { PAK, TUR }\end{array}$ \\
\hline 1998 & $\begin{array}{l}\text { KAZ, IRN, BLR, ROU, TKM, } \\
\text { RUS, UKR, POL, ZB }\end{array}$ & $\begin{array}{l}\text { EGY, JPN, MYS, PHL, SAU, } \\
\text { KOR, THA }\end{array}$ & IDN, VNM, CZE, BGR, IND & $\begin{array}{l}\text { ARE, ISR, SVK, HUN, BGD, } \\
\text { SGP, PAK, TUR }\end{array}$ \\
\hline 2002 & $\begin{array}{l}\text { KAZ, IRN, BLR, ROU, KM, } \\
\text { RUS, UKR, UZB }\end{array}$ & $\begin{array}{l}\text { EGY, JPN, IDN, MYS, KOR, } \\
\text { THA, SGP, CZE }\end{array}$ & VNM, SAU, BGR, IND & $\begin{array}{l}\text { ARE, PHL, ISR, SVK, HUN, } \\
\text { BGD, SGP, PAK, TUR }\end{array}$ \\
\hline 2006 & $\begin{array}{l}\text { KAZ, IRN, BLR, TKM, US, } \\
\text { THA, PAK, UZB }\end{array}$ & $\begin{array}{l}\text { JPN, IDN, SVK, KOR, } \\
\text { SGP, CZE }\end{array}$ & $\begin{array}{l}\text { EGY, MYS, VNM, AU, UKR, } \\
\text { BGR, IND }\end{array}$ & $\begin{array}{l}\text { ARE, PHL, ISR, ROU, HUN, } \\
\text { BGD, TUR, POL }\end{array}$ \\
\hline 2010 & $\begin{array}{l}\text { KAZ, IRN, BLR, TKM, US, } \\
\text { THA, PAK, UZB }\end{array}$ & $\begin{array}{l}\text { JPN, IDN, SVK, HUN, OR, } \\
\text { SGP, CZE }\end{array}$ & $\begin{array}{l}\text { EGY, MYS, VNM, AU, UKR, } \\
\text { BGR, IND }\end{array}$ & $\begin{array}{l}\text { ARE, PHL, ISR, ROU, BGD, } \\
\text { TUR, POL }\end{array}$ \\
\hline 2014 & $\begin{array}{l}\text { KAZ, IRN, BLR, TKM, US, } \\
\text { UKR, UZB }\end{array}$ & $\begin{array}{l}\text { JPN, IDN, ROU, SVK, HUN, } \\
\text { KOR, CZE }\end{array}$ & $\begin{array}{l}\text { EGY, MYS, VNM, SAU, } \\
\text { UKR, BGR, IND }\end{array}$ & $\begin{array}{l}\text { ARE, PHL, ISR, BGD, SGP, } \\
\text { TUR, POL }\end{array}$ \\
\hline
\end{tabular}

Table 4. Local Moran' I values in the key time points.

\begin{tabular}{|c|c|c|c|c|c|c|c|c|}
\hline \multirow{2}{*}{ Time Point } & \multicolumn{6}{|c|}{ HH Agglomeration } & \multicolumn{2}{|c|}{ LL Agglomeration } \\
\hline & Area & Local Moran's I & Area & Local Moran's I & Area & Local Moran's I & Area & Local Moran's I \\
\hline \multirow{2}{*}{1995} & KAZ & $1.779(0.003)^{* * *}$ & RUS & $1.204(0.011)^{* *}$ & UZB & $2.516(0.000)^{* * *}$ & JPN & $2.560(0.004)^{* * *}$ \\
\hline & BLR & $0.898(0.041)^{* *}$ & UKR & $0.695(0.021)^{* *}$ & - & - & KOR & $2.560(0.004)^{* * *}$ \\
\hline \multirow{2}{*}{1998} & KAZ & $1.844(0.003)^{* * *}$ & RUS & $1.569(0.001)^{* * *}$ & UZB & $2.646(0.000)^{* * *}$ & JPN & $1.525(0.053) *$ \\
\hline & BLR & $0.865(0.047)^{* *}$ & UKR & $0.521(0.060) *$ & - & - & KOR & $1.525(0.053)$ * \\
\hline \multirow{2}{*}{2002} & KAZ & $2.131(0.001)^{* * *}$ & TKM & $0.849(0.050)$ * & UZB & $3.310(0.000)^{* * *}$ & JPN & $1.928(0.021)^{* *}$ \\
\hline & BLR & $0.790(0.063) *$ & RUS & $1.428(0.003)^{* * *}$ & - & - & KOR & $1.928(0.021)^{* *}$ \\
\hline \multirow{2}{*}{2006} & KAZ & $1.583(0.008)^{* * *}$ & RUS & $0.716(0.081) *$ & UZB & $3.275(0.000) * * *$ & JPN & $1.795(0.029)^{* *}$ \\
\hline & TKM & $1.155(0.013)^{* *}$ & - & - & - & - & KOR & $1.795(0.029)^{* *}$ \\
\hline \multirow{2}{*}{2010} & KAZ & $1.561(0.009)^{* * *}$ & RUS & $0.765(0.069)$ * & UZB & $2.819(0.000)^{* * *}$ & - & - \\
\hline & TKM & $0.688(0.091) *$ & - & - & - & - & - & - \\
\hline 2014 & KAZ & $1.109(0.046)^{* *}$ & UZB & $2.038(0.001)^{* * *}$ & - & - & - & - \\
\hline
\end{tabular}

Notes: ${ }^{*}{ }^{* *}$ and ${ }^{* *}$ donate the rejection of null hypothesis at $10 \%, 5 \%$ and $1 \%$, respectively. Only the countries that pass the significance test are listed in the table and numbers in parentheses are the $p$-values of the Z-statistics.

(2) The HH-typed agglomeration areas are mainly eastern European and central Asian countries, showing that the countries with high carbon intensities are surrounded by those with high carbon intensities. Among them, KAZ and UZB, which are both located in central Asia, have consistently high carbon intensities. For example, in 2014, the local Moran's I values in KAZ and UZB were 1.109 and 2.038 , which are in a high level. Hence, it can be inferred that the two countries have significant radiation effect on surrounding areas, meaning that the high carbon intensities in KAZ and UZB can 
push the increase of carbon intensities in the neighboring countries. Besides, RUS's carbon intensity has also been high, and the local Moran's $I$ is significantly greater than 0 at most time points, indicating that the radiation effect is obvious in RUS, that is, RUS plays a significant role in promoting the increase of carbon intensities in its surrounding countries.

(3) The LL-typed areas are mainly located in eastern European countries and east and southeastern Asian countries, indicating that the countries with low carbon intensities trend to gather together. Among them, JPN and KOR, which are both developed countries and located in eastern Asia, have always had low carbon intensities and significant local Moran's I in 1995, 1998, 2002 and 2006, showing a strong radiation effects on surrounding areas. JPN and KOR are developed countries with high economic development levels and advanced technological levels, resulting that the carbon intensities in surrounding countries are significantly influenced by them, developing towards the low carbon intensity. However, after 2010, the radiation effects of JPN and KOR are no longer significant, showing that no country has significant effects on surrounding countries to promote them to develop a GELC economy, which is not conducive to achieving the goal of global GELC development. The reason for this phenomenon is that after the global financial crisis in 2008, JPN and KOR suffered great losses, resulting that their driving roles played for the surrounding area was greatly reduced. Meanwhile, in order to recover from the crisis as quickly as possible, east and southeastern Asian countries have adopted extensive economic development modes to exchange for the rapid development of economic law at the expense of resources and environment, making it difficult for JPN and KOR to promote the GELC development of these countries.

\section{Spatial Convergence Model of Carbon Intensity}

\subsection{Conventional Panel Convergence Model}

Convergence means that observations with unequal absolute values in different regions tend to the same stable equilibrium value statistically [63]. Convergence theory was originally used to study the convergence of per capita income in different countries or regions [64], and was subsequently widely used in convergence of energy, trade, and environmental indicators [65-67]. In general, there are three main convergence theories: $\sigma$ convergence, $\beta$ convergence and club convergence. $\sigma$ convergence is mainly based on the trends of the standard deviation or coefficient of variation of the observed values [68]. If the standard deviation or coefficient of variation decreases, it indicates that there is $\sigma$ convergence, and vice versa. $\beta$ convergence and club convergence are based on the coefficient determination results of the regression equation. If the regression coefficient is significantly negative, it indicates that there is $\beta$ convergence or club convergence. The theoretical basis of $\beta$ convergence and club convergence is that the observed values in different regions have a negative correlation with the average growth rate of observations [69], that is, regions with high observation values have low growth rates and regions with low observations have high growth rates, indicating that laggards have a "catch-up effect" with advanced individuals. The difference between $\beta$ and club convergence theories is that $\beta$ convergence is used to verify whether observations of all objects converge to the same stable value, while club convergence assumes that the observed values of objects at different levels of observations may converge to different local stable values, and the convergence rate will be different $[69,70]$.

This paper mainly adopts the $\beta$ convergence theory to study whether the carbon intensity of the $B \& R$ countries tends to the same stable equilibrium value. $\beta$ convergence can be divided into absolute convergence and conditional convergence. Absolute convergence assumes that the different regions have the same internal or external conditions, or that the internal and external conditions have no influence on the convergence of the observations [71]. For panel data, the conventional absolute $\beta$ convergence model can be expressed as:

$$
g_{i, t+1}=\alpha+\left(e^{-\theta T}-1\right) \ln T_{i, t}+\mu_{t}+v_{i}+\varepsilon_{i, t}
$$


where $T$ is the length of the observation period, $g_{i, t+1}=\left(\ln Y_{i, t+T}-\ln Y_{i, t}\right) / T$ means the average growth rate of observations during the period of $t+1, Y_{i, t+T}$ and $Y_{i, t}$ represent the observations of region $i$ in period $t+T$ and $t, t+1, \mu_{t}$ and $v_{i}$ are the time and individual fixed effects, $\alpha$ is parameter to be estimated and $\theta$ is the speed in which $Y_{i, t}$ converges to the steady state. Introducing a parameter $\beta$ and letting $\beta=-\left(1-e^{-\theta T}\right)$, then Equation (5) can be written as:

$$
\frac{1}{T} \ln \left(\frac{Y_{i, t+T}}{Y_{i, t}}\right)=\alpha+\beta \ln T_{i, t}+\mu_{t}+v_{i}+\varepsilon_{i, t}
$$

As shown in Equation (6), $\beta<0$ means that there is absolute $\beta$ convergence and the convergence speed is $\theta$, and $\beta>0$, it means there is no absolute $\beta$ convergence. According to the estimation result of $\beta, \theta$ can be obtained by [71]:

$$
\theta=-\operatorname{In}(1+T \beta) / T
$$

Moreover, some researchers put forward the concept of half- period of convergence to reflect the speed of convergence, which refers to the time required to eliminate half of the gap between laggards and advanced individuals. The equation for the half-period is [71]:

$$
\zeta=-\ln 2 / \ln (1+\beta)
$$

Conditional $\beta$ convergence assumes that the internal or external factors have significant influence on the convergence of observations. The conditional $\beta$ convergence model for panel data is expressed as below:

$$
\frac{1}{T} \ln \left(\frac{Y_{i, t+T}}{Y_{i, t}}\right)=\alpha+\beta \ln Y_{i, t}+\gamma X_{i, t}+\mu_{t}+v_{i}+\varepsilon_{i, t}
$$

where $X_{i, t}$ is the internal or external factor influencing the convergence of $Y_{i, t}$ and $\gamma$ is the parameter reflecting the influence degree of $X_{i, t}$. Similarly, in Equation (9), $\beta<0$ means that there is conditional $\beta$ convergence. Otherwise, there isn't conditional $\beta$ convergence. Meanwhile, the half-period of conditional $\beta$ convergence can be calculated by Equation (8). More generally, make the length of the observation period be 1 , the classical absolute and conditional $\beta$ convergence models can be:

$$
\begin{aligned}
& \Delta \ln Y_{i, t+1}=\alpha+\beta \ln Y_{i, t}+\mu_{t}+v_{i}+\varepsilon_{i, t} \\
& \Delta \ln Y_{i, t+1}=\alpha+\beta \ln Y_{i, t}+\mu_{t}+v_{i}+\varepsilon_{i, t}
\end{aligned}
$$

where $\Delta \ln Y_{i, t+1}=\ln \left(\frac{Y_{i, t+1}}{Y_{i, t}}\right)$, indicating the annual growth rate of $Y_{i, t}$.

\subsection{Spatial Panel $\beta$ Convergence Model}

However, the conventional panel $\beta$ convergence models do not take into account the influence of spatial factors. In fact, ignoring spatial factors will lead to biased model setting and ultimately result in misjudgment of results [72,73]. As mentioned before, the carbon intensities in the examined $B \& R$ countries are spatially dependent, revealing that the spatial panel convergence approaches are needed. In this section, several spatial $\beta$ convergence models are employed to investigate the convergence of carbon intensity in $29 \mathrm{~B} \& \mathrm{R}$ countries involving spatial auto-regression model (SAR), spatial error model (SEM), and spatial Durbin model (SDM) [74-76]. Normally, the absolute spatial $\beta$ convergence model can be:

$$
\begin{gathered}
\mathrm{SAR}: \Delta \ln Y_{i, t+1}=\alpha+\beta \ln Y_{i, t}+\rho \sum_{j} w_{i, j} \Delta \ln Y_{j, t+1}+\mu_{t}+v_{i}+\varepsilon_{i, t} \\
\mathrm{SAR}: \Delta \ln Y_{i, t+1}=\alpha+\beta \ln Y_{i, t}+\mu_{t}+v_{i}+\epsilon_{i, t} \epsilon_{i, t}=\lambda \sum_{j} w_{i, j} \epsilon_{j, t}+\varepsilon_{i, t} \\
\mathrm{SDM}: \Delta \ln Y_{i, t+1}=\alpha+\beta \ln Y_{i, t}+\rho \sum_{j} w_{i, j} \Delta \ln Y_{j, t+1}+\psi \sum_{j} w_{i, j} \ln Y_{j, t}+\mu_{t}+v_{i}+\varepsilon_{i, t}
\end{gathered}
$$


where $Y_{i, t}$ is the observation of the $i$-th region in period $t, \varepsilon_{i, t}$ is a white noise and $\varepsilon_{i, t}$ means the error term with spatial autocorrelation $\rho$ represents the spatial auto-regression coefficient, $\epsilon$ means the spatial autocorrelation coefficient of error item and $\psi$ is the spatial lag coefficient of $\ln Y_{i, t}$. In addition, $w_{i, j}$ is the element in spatial weight matrix, therefore $\sum_{j} w_{i, j} \Delta \ln Y_{j, t+1}$ reveals the spatial effects of the observation in regions which are adjacent to region $i$ on that in region $i$.

For conditional spatial $\beta$ convergence, the SAR, SEM and SDM can be:

$$
\begin{gathered}
\mathrm{SAR}: \Delta \ln Y_{i, t+1}=\alpha+\beta \ln Y_{i, t}+\gamma X_{i, t}+\rho \sum_{j} w_{i, j} \Delta \ln Y_{j, t+1}+\mu_{t}+v_{i}+\varepsilon_{i, t} \\
\begin{aligned}
\mathrm{SEM}: \Delta \ln Y_{i, t+1}=\alpha+\beta \ln Y_{i, t}+\gamma X_{i, t}+\mu_{t}+v_{i}+\epsilon_{i, t}, \epsilon_{i, t}=\lambda \sum_{j} w_{i, j} \epsilon_{j, t}+\varepsilon_{i, t} \\
\mathrm{SDM}: \Delta \ln Y_{i, t+1}=\alpha+\beta \ln Y_{i, t}+\gamma X_{i, t}+\psi \sum_{j} w_{i, j} \ln Y_{j, t}+\rho \sum_{j} w_{i, j} \Delta \ln Y_{j, t+1} \\
+\phi \sum_{j} w_{i, j} X_{j, t}+\mu_{t}+v_{i}+\varepsilon_{i, t}
\end{aligned}
\end{gathered}
$$

where $\gamma$ is the coefficient of control variable and $\phi$ is the spatial lag coefficient of control variable. Similarly, if $\beta<0$, it indicates that there is $\beta$ convergence. Otherwise, there isn't $\beta$ convergence.

Normally, most scholars examine the spatial $\beta$ convergence applying SAR or SEM. In fact, SDM is a more general model which can be simplified to SAR or SEM under certain conditions. Specifically, for absolute spatial $\beta$ convergence model, in Equation (14) when $\psi=0$, the SDM is equivalent to SAR, and when $\psi+\rho \beta=0$, the SDM is equivalent to SEM [72]. For conditional spatial $\beta$ convergence model, supposing that $\operatorname{In} Y_{i, t}$ is one of the explanatory variables, a general SDM based on Equation (17) can be expressed as below:

$$
\Delta \ln Y_{i, t+1}=\alpha+_{i, t} Y+\sum_{j=1}^{n} w_{i, j} H_{j, t} \Theta+\rho \sum_{j=1}^{n} w_{i, j} \Delta \ln Y_{j, t+1}+c_{i}+\mu_{t}+\varepsilon_{i, t}
$$

where $i, t$ is a row vector representing all explanatory variables, $\mathrm{Y}$ and $\Theta$ are column vectors indicating the coefficients. According to Anselin [72], the SDM can be simplified to SAR when the null hypothesis that $\Theta=0$ is accepted. If the null hypothesis that $\Theta+\rho \mathrm{Y}=0$ is accepted, it means the SDM can be simplified to SEM. Generally, Wald and likelihood ratio (LR) tests can be adopted to examine the two null hypothesizes, as suggested by Anselin [72] and Mur and Angulo [77].

\section{Empirical Results and Interpretations}

\subsection{Variables, Data and Descriptive Statistics}

This section applies the spatial panel convergence model constructed above to test the convergence of carbon intensity in the analyzed 29 B\&R countries during 1995-2014. There are many factors affecting carbon intensity, and related researches are mainly based on IPAT model, STIRPAT model and Kaya identity. IPAT was proposed by Enrlin and Holdren [78] in 1971 to study the environmental issues, and then York et al. made some improvements and proposed the STIRPAT model [79], which considered that the main factors affecting the environment include population, economy and technology. The Kaya identity breaks down the main factors affecting carbon intensity into the product of population, per capita GDP, energy intensity and carbon emissions per unit of energy $[80,81]$. Based on the above researches and the analysis of the factors affecting carbon intensity, this article summarizes the influencing factors in two aspects. That is, the internal factors which mainly reflect the characteristics of the $B \& R$ countries, and the external factors that mainly reflect the influence of the $B \& R$ Initiative on the countries along the route.

For the internal factors, five indicators are selected, including per capita GDP, population density, industrial structure, national modernization and energy consumption structure, and the qualitative description of each indicator is as follows: 
(1) Per capita GDP (PGDP, 2005 constant US dollars): GDP can represent the economic development level of a country. However, because the population of each country is very different, the reflection of this indicator is not comprehensive enough. Therefore, we choose per capita GDP to reflect the economic development levels of different countries, and the data are collected from World Bank database (https:/ / data.worldbank.org.cn).

(2) Population density $\left(P D\right.$, people per $\left.\mathrm{km}^{2}\right)$. The spatial distribution of the population is an important factor affecting the intensity of carbon emissions. Generally speaking, population density will significantly affect the level of carbon emissions in the region, and thus affect the carbon intensity. The population density of each country is obtained by dividing the total population by the land area. The data comes from the World Bank.

(3) We use the "second industry size change" to approximate the "industry structure" (IS, \%), which is defined as the ratio of industrial added value to GDP (both in 2005 constant US dollars). The data is available in both the World Bank database and the UN database. Since most of the indicators in this article are obtained from the World Bank, in order to maintain consistency in the sources of statistical data, we have chosen the World Bank as the main source of the indicator data, and then we filled it up with multiple trapping analysis methods. For countries that still have missing data after supplementing data, we use the corresponding data from the UN database to supplement it again.

(4) According to the World Bank, the number of non-high-income countries accounted for $70.91 \%$ of the total major B\&R countries. Therefore, taking into account the different development levels in these countries, we use the indicators of urbanization process to measure differences in the level of national modernization. The urbanization process is measured by the urbanization rate $(U R, \%)$, that is, the ratio of urban population to total population, and the data comes from World Bank database.

(5) For the energy consumption structure, our measurement process and measurement process are as follows: In the academic community's research on energy consumption and carbon intensity, the selected research samples are mostly concentrated in a country-wide sub-region, a world-wide sub-region, or a similar national and regional group [82-84]. In this way, the selected sample's resource endowments are usually very close due to the highly similar geographical environment, resulting in a very close energy consumption structure of the sample, so it can use the proportion of certain energy in total energy to reflect the energy consumption structure, and this indicator is usually the ratio of coal consumption to total energy consumption. The main B\&R countries straddle the three continents of Europe, Asia and Africa, whose resource endowments are quite different and can be classified as coal, oil and natural gas, according to Li X and Wang Y [85]. In order to better reflect the impact of energy consumption structure on carbon intensity, we have transformed the "energy consumption structure" into "concentration of carbon in consumed energy" (CCCE, kg carbon emissions per koe), which can be expressed as $\sum_{j} a_{j} b_{j}$, where $a_{j}$ is the carbon emission coefficient of $j$-th fuel, and $b_{j}$ is the ratio of $j$-th fuel consumption to the total energy consumption in the country. The carbon emission coefficient comes from the United Nations Emission Factor Database, and the energy consumption data is collected from World Bank.

For the external factors, the two indicators named investment rate and openness are selected, so as to reflect the effect of $B \& R$ Initiative on the carbon intensities in the examined countries. The qualitative descriptions are as below:

(1) The investment rate $(I R, \%)$ includes foreign investment and domestic investment, of which foreign investment is measured by foreign direct investment, and we use the term "net foreign direct investment inflows (\% of GDP)" as an approximate measure. Domestic investment is defined as "total capital formation (\% of GDP)" which was formerly known as total domestic investment. All data is collected from World Bank database. 
(2) Openness $(O P, \%)$ is measured by the degree of external dependence, that is, the ratio of trade volume to GDP, in which trade volume refers to the imports and exports of goods and services. All data is obtained from World Bank.

Besides, the carbon intensity $(C I)$ in the studied B\&R countries is obtained from the World Bank database. To eliminate the heteroscedasticity of data, the paper takes the natural logarithm of $C I$, $P G D P$ and $P D$, recorded as $L C I, L P G D P$ and $L P D$, and the descriptive statistics of all variables in panel are listed in Table 5.

Table 5. Descriptive statistics for all variables in panel.

\begin{tabular}{ccccccc}
\hline Variable & Observations & Mean & Median & Maximum & Minimum & Std. Dev. \\
\hline LCI & 580 & 1.944365 & 1.947738 & 2.265970 & 0.803268 & 0.137842 \\
LPGDP & 580 & 8.288283 & 8.320723 & 10.93363 & 5.619497 & 1.354522 \\
LPD & 580 & 4.641461 & 4.715726 & 8.940724 & 1.705420 & 1.453405 \\
$I S$ & 580 & 0.358313 & 0.350944 & 0.688223 & 0.201975 & 0.085027 \\
UR & 580 & 0.590458 & 0.608920 & 1.000000 & 0.216930 & 0.194272 \\
CCCE & 580 & 0.759729 & 0.731715 & 0.991193 & 0.587564 & 0.087592 \\
$I R$ & 580 & 0.273064 & 0.267798 & 0.740582 & -0.0116684 & 0.087524 \\
OP & 580 & 0.817737 & 0.689534 & 3.454172 & 0.142959 & 0.543581 \\
\hline
\end{tabular}

\subsection{Absolute $\beta$ Convergence Results}

To determine the existence of country and time fixed effects, a non-spatial panel OLS estimation method is performed in this section first to examine the convergence of carbon intensity in the $29 \mathrm{~B} \& \mathrm{R}$ countries, and the results are reported in Table 6, from which it can be seen that country-fixed and time-fixed effects should be involved in the model at the same time, because the Log-likelihood value and adjusted R-squared value of both-fixed model are the largest among the four models. For robust, the joint significance of country-fixed effect and time-fixed effect is examined using LR test, and the results are listed in Table 7, showing that the model should be both-fixed including country-fixed and time-fixed effects.

Table 6. OLS estimation and test results of absolute convergence of carbon intensity ( $p$-values in parentheses).

\begin{tabular}{|c|c|c|c|c|}
\hline Variable & No-Fixed Effect & Country-Fixed Effect & Time-Fixed Effect & Both-Fixed Effect \\
\hline Constant & 0.0211 & - & - & - \\
\hline \multirow{2}{*}{$L C I$} & -0.0150 & -0.0148 & -0.0222 & -0.0521 \\
\hline & $(0.0199)^{* *}$ & $(0.1753)$ & $(0.0006)^{* * *}$ & $(0.0004)^{* * *}$ \\
\hline Log-likelihood & 1353.597 & 1363.485 & 1423.246 & 1438.848 \\
\hline R-squared & 0.0098 & 0.0447 & 0.2310 & 0.2734 \\
\hline \multirow{2}{*}{$\begin{array}{c}\text { Adjusted R-squared } \\
\text { sigma }\end{array}$} & 0.0080 & -0.0084 & 0.2035 & 0.2055 \\
\hline & 0.0208 & 0.0210 & 0.0186 & 0.0186 \\
\hline \multirow{2}{*}{ LM-lag } & 63.6481 & 52.1204 & 62.6835 & 63.3842 \\
\hline & $(0.0000)^{* * *}$ & $(0.0000)^{* * *}$ & $(0.0000)^{* * *}$ & $(0.0000)^{* * *}$ \\
\hline \multirow{2}{*}{ Robust LM-lag } & 1.0127 & 0.1960 & 0.0042 & 0.0275 \\
\hline & $(0.3134)$ & $(0.6580)$ & $(0.9483)$ & $(0.8683)$ \\
\hline \multirow{2}{*}{ LM-error } & 63.9470 & 65.3426 & 62.6799 & 82.3607 \\
\hline & $(0.0000)^{* * *}$ & $(0.0000)^{* * *}$ & $(0.0000)^{* * *}$ & $(0.0000)^{* * *}$ \\
\hline \multirow{2}{*}{ Robust LM-error } & 1.3115 & 13.4182 & 0.0006 & 19.0040 \\
\hline & $(0.2521)$ & $(0.0002)^{* * *}$ & $(0.9800)$ & $(0.0000)^{* * *}$ \\
\hline
\end{tabular}

Notes: ${ }^{* *}$ and ${ }^{* * *}$ donate the rejection of null hypothesis at $5 \%$ and $1 \%$, respectively.

As shown in Table 6, the spatial diagnosis results of the OLS estimation of both-fixed effect model show that the LM-lag and LM-error statistics are both significant, indicating that the spatial effects cannot be ignored when examining the absolute convergence of carbon intensities in B\&R countries. This conclusion is consistent with the results of Moran's I showing a significantly positive spatial correlation among carbon intensities in B\&R countries. Furthermore, the robust LM-lag statistic is not significant while the robust LM-error statistic is significant, revealing that when employing spatial 
econometric model to investigate the absolute convergence of carbon intensities in B\&R countries, SEM is superior to SAR.

Table 7. Combined significance test results of province and time fixed effects for absolute convergence.

\begin{tabular}{cccc}
\hline Fixed effect & LR Statistic & d.f. & Prob. \\
\hline Country fixed effect & 51.203784 & 28 & $0.0047^{* * *}$ \\
Time fixed effect & 150.725754 & 18 & $0.0000^{* * *}$ \\
\hline
\end{tabular}

Notes: ${ }^{* * *}$ donates the rejection of null hypothesis at $1 \%$, d.f. means the degree of freedom, and Prob. means $p$-value of significance test.

As mentioned above, the spatial effects influence the convergence of carbon intensities in B\&R countries significantly, so the both-fixed spatial econometric models like SAR, SEM and SDM are employed in this section to explore the absolute convergence of carbon intensities in the examined 29 B\&R countries. The empirical results are reported in Table 8, from which it can be seen that after the inclusion of spatial effects, the adjusted R-squared and Log-likelihood value both increases, indicating that introducing spatial effects has improved the authenticity and scientific soundness of the model. What's more, according to the results of Wald and LR tests shown in Table 8, the applicability tests of SDM accept the null hypothesis, revealing that the SDM could be simplified to SAR or SEM. According to Table 6 showing that SEM is superior to SAR when exploring the absolute convergence of the B\&R countries' carbon intensities, SEM will be used to accomplish the absolute convergence analysis next.

Table 8. Estimation results of absolute convergence of carbon intensity ( $p$-values in parentheses).

\begin{tabular}{|c|c|c|c|}
\hline Variable & SAR & SEM & SDM \\
\hline$L C I$ & $\begin{array}{c}-0.0512 \\
(0.0000)^{* * *}\end{array}$ & $\begin{array}{c}-0.0530 \\
(0.0000)^{* * *}\end{array}$ & $\begin{array}{c}-0.0544 \\
(0.0000)^{* * *}\end{array}$ \\
\hline$\sum_{j} w_{i, j} L C I_{j, t}$ & - & - & $\begin{array}{c}0.0158 \\
(0.0518) *\end{array}$ \\
\hline$\sum_{j} w_{i, j} \Delta L C I_{j, t+1}$ & $\begin{array}{c}0.1243 \\
(0.0067)^{* * *}\end{array}$ & - & $\begin{array}{c}0.1289 \\
(0.0054)^{* * *}\end{array}$ \\
\hline$\sum_{j} w_{i, j} \epsilon_{j, t}$ & - & $\begin{array}{c}0.1276 \\
(0.0057)^{* * * *}\end{array}$ & - \\
\hline Log-likelihood & 1442.4427 & 1442.5818 & 1442.6501 \\
\hline R-squared & 0.3790 & 0.3562 & 0.3223 \\
\hline Adjusted R-squared & 0.2098 & 0.2148 & 0.2106 \\
\hline sigma & 0.0176 & 0.0176 & 0.0176 \\
\hline \multicolumn{4}{|c|}{ Applicability tests of SDM } \\
\hline Method & \multicolumn{2}{|c|}{ Statistics } & Prob. \\
\hline Wald spatial lag & \multicolumn{2}{|c|}{2.1276} & 0.1447 \\
\hline LR spatial lag & \multicolumn{2}{|c|}{2.3283} & 0.1270 \\
\hline Wald spatial error & \multicolumn{2}{|c|}{1.8095} & 0.1786 \\
\hline LR spatial error & \multicolumn{2}{|c|}{1.7174} & 0.1900 \\
\hline
\end{tabular}

As shown in Table 8, the coefficient of $L C I$ of SEM is significantly negative, revealing that a significant absolute $\beta$ convergence of carbon intensities in the analyzed $29 \mathrm{~B} \& \mathrm{R}$ countries emerges, that is, the countries with high carbon intensities have lower growth rates of carbon intensities while the countries with low carbon intensities have higher ones. Meanwhile, based on Equations (7) and (8), the speed of absolute $\beta$ convergence is 0.0545 and the half-period of convergence is 12.73 years, showing that the carbon intensities in B\&R countries will converge to a steady state in the foreseeable future. Besides, the coefficient of $\sum_{j} w_{i, j} \epsilon_{j, t}$ is significantly positive, meaning that there is a positive 
correlation between carbon intensities in different countries, that is, during 1995-2014, the carbon intensity in a country is positively affected by the changes of carbon intensities in the adjacent countries.

\subsection{Conditional $\beta$ Convergence Results $\beta$}

Similar to the analysis of absolute $\beta$ convergence, a non-spatial panel OLS estimation method is performed in this section first to determine the existence of country and time fixed effects when investigating the convergence of carbon intensity in the $29 \mathrm{~B} \& \mathrm{R}$ countries. The estimation results of the four models, no effect model, country-fixed effect model, time-fixed model and both-fixed model, are represented in Table 9, showing that the Log-likelihood value and adjusted R-squared value of both-fixed model are the largest among the four models, so the country-fixed and time-fixed effects should be considered when exploring the conditional convergence in this section. Meanwhile, the results of LR test, which is adopted to test the joint significance of country-fixed effect and time-fixed effect, are reported in Table 10, supporting the same opinion that both country-fixed and time-fixed effects should be involved in the model.

Table 9. OLS estimation and test results of conditional convergence of carbon intensity ( $p$-values in parentheses).

\begin{tabular}{|c|c|c|c|c|}
\hline Variable & No Effect & Country-Fixed Effect & Time-Fixed Effect & Both Fixed Effect \\
\hline Constant & 0.0512 & - & - & - \\
\hline \multirow{2}{*}{ LCI } & -0.0472 & -0.0936 & -0.0713 & -0.0948 \\
\hline & $(0.0326)^{* *}$ & $(0.0035)^{* * *}$ & $(0.0092)^{* * *}$ & $(0.0017)^{* * *}$ \\
\hline \multirow{2}{*}{$L P G D P$} & -0.0020 & -0.0039 & -0.0010 & 0.0070 \\
\hline & $(0.0245)^{* *}$ & $(0.0195)^{* *}$ & $(0.0499) * *$ & $(0.0111) * *$ \\
\hline \multirow{2}{*}{$L P D$} & 0.0007 & -0.0208 & 0.0004 & 0.0274 \\
\hline & $(0.0686) *$ & $(0.0393)^{* *}$ & $(0.0809) *$ & $(0.0262)^{* *}$ \\
\hline \multirow[b]{2}{*}{ IS } & 0.0188 & 0.0034 & 0.0163 & -0.0280 \\
\hline & $(0.0784) *$ & $(0.0904) *$ & $(0.0975)^{*}$ & $(0.0920) *$ \\
\hline \multirow{2}{*}{$U R$} & 0.0024 & -0.0214 & -0.0031 & 0.0551 \\
\hline & $(0.7714)$ & $(0.0619) *$ & $(0.0808) *$ & $(0.0042)^{* * *}$ \\
\hline \multirow{2}{*}{ CCCE } & 0.6108 & 1.1191 & 0.0214 & -3.4515 \\
\hline & $(0.0651) *$ & $(0.0813) *$ & $(0.0982) *$ & $(0.0298)^{* *}$ \\
\hline \multirow[b]{2}{*}{$I R$} & -0.0116 & -0.0107 & -0.0062 & -0.0089 \\
\hline & $(0.2966)$ & $(0.0493)^{* *}$ & $(0.0500) *$ & $(0.0815) *$ \\
\hline \multirow{2}{*}{$O P$} & -0.0033 & -0.0168 & -0.0024 & -0.0034 \\
\hline & $(0.0791) *$ & $(0.0027)^{* * *}$ & $(0.0203) * *$ & $(0.0829) *$ \\
\hline Log-likelihood & 1359.154 & 1374.619 & 1427.710 & 1443.274 \\
\hline R-squared & 0.0296 & 0.0826 & 0.2434 & 0.2849 \\
\hline \multirow{2}{*}{$\begin{array}{c}\text { Adjusted R-squared } \\
\text { sigma }\end{array}$} & 0.0153 & 0.0183 & 0.2058 & 0.2071 \\
\hline & 0.0207 & 0.0207 & 0.0186 & 0.0186 \\
\hline \multirow{2}{*}{ LM-lag } & 59.3619 & 13.0775 & 77.0003 & 75.4821 \\
\hline & $(0.0000)^{* * *}$ & $(0.0003)^{* * *}$ & $(0.0000)^{* * *}$ & $(0.0000)^{* * *}$ \\
\hline \multirow{2}{*}{ Robust LM-lag } & 1.7044 & 0.0334 & 13.0456 & 8.6514 \\
\hline & $(0.1917)$ & $(0.8550)$ & $(0.0003)^{* * *}$ & $(0.0033) * * *$ \\
\hline \multirow{2}{*}{ LM-error } & 58.2081 & 49.8781 & 74.6167 & 72.7523 \\
\hline & $(0.0000) * * * *$ & $(0.0000) * * *$ & $(0.0000) * * *$ & $(0.0000) * * *$ \\
\hline \multirow{2}{*}{ Robust LM-error } & 0.5506 & 16.8340 & 10.6621 & 5.9216 \\
\hline & $(0.4581)$ & $(0.0000)^{* * *}$ & $(0.0011)^{* * *}$ & $(0.0058)^{* * *}$ \\
\hline
\end{tabular}

Notes: ${ }^{* * *}$ and ${ }^{* * *}$ donate the rejection of null hypothesis at $10 \%, 5 \%$ and $1 \%$, respectively.

Table 10. Combined significance test results of province and time fixed effects for conditional convergence.

\begin{tabular}{cccc}
\hline Fixed effect & LR Statistic & d.f. & Prob. \\
\hline Country fixed effect & 61.127822 & 28 & $0.0003^{* * *}$ \\
Time fixed effect & 137.308858 & 14 & $0.0000^{* * *}$ \\
\hline *** donates the rejection of null hypothesis at 1\%, d.f. means the degree of freedom.
\end{tabular}

Furthermore, the spatial correlation test of the OLS estimation of both-fixed effect model is performed and the results are listed in Table 6, from which it can be inferred that the LM-lag 
and LM-error statistics are both significant, revealing that the spatial effects affect the conditional convergence of carbon intensities in the analyzed $29 \mathrm{~B} \& \mathrm{R}$ countries significantly, which is consistent with the results of Moran's I. Besides, the robust LM-lag and robust LM-error statistics are both significant too, but the p-value of robust LM-lag is less than that of robust LM-error, indicating that SAR is more suitable for investigating the conditional $\beta$ convergence of carbon intensities than SEM.

The estimation results of the spatial convergence models (SAR, SEM and SDM) with both-fixed effects are reported in Table 11, showing that the introduction of spatial effects increased the adjusted R-squared value and the Log-likelihood value, that is, make the model more scientific and reliable. Besides, the applicability tests of SDM based on Wald and LR tests shows that the null hypothesis that the SDM can be simplified to SAR or SEM is rejected, indicating that SDM should be applied to examine the conditional convergence of carbon intensities in the $29 \mathrm{~B} \& \mathrm{R}$ countries.

According to Table 11, the coefficient of $L C I$ in SDM is -0.0956 , which is significantly negative, revealing that there exists a conditional $\beta$ convergence in the examined carbon intensities. Similarly, the convergence speed of conditional $\beta$ convergence is calculated via Equation (7) and the half-period of conditional $\beta$ convergence is obtained through Equation (8), which are 0.1005 and 6.90 years respectively, much shorter than that of absolute $\beta$ convergence. The results support that the carbon intensities in the $29 \mathrm{~B} \& \mathrm{R}$ countries will converge to a steady state in a faster speed when the differences in different countries are considered, that is, the internal and external factors have significant effects on the convergence of $B \& R$ countries' carbon intensities.

Specifically, (1) LPGDP, LPD and UR have significant positive influence on the change of carbon intensity, that is, the increase of economic development level, population and urbanization rate will increase the growth rate of carbon intensity, which is not conducive to the convergence of carbon intensity; (2) The coefficients of IS, CCCE, IR and OP are negative and significant, indicating that the optimization of industrial structure and energy consumption structure can decline the growth rate of carbon intensity, thus promote the convergence of carbon intensity. Besides, the investment rate and openness play a driving role in pushing the decrease of carbon intensity growth rate, which helps to achieve the convergence. This result supports that the B\&R Initiative can promote GELC development of $B \& R$ countries by decreasing the growth rate of carbon intensity; (3) The spatial effect of LPD has no effect on the change of carbon intensity, revealing that the carbon intensity in a country will not be affected by the population in the adjacent countries; (4) The spatial effects of $L C I, L P G D P$ and UR have positively significant influence on the change of carbon intensity growth rate, revealing that the increase of carbon intensity, economic development level and urbanization rate in the surrounding countries can increase the growth rate of carbon intensity in the country; (5) The spatial effects of $I S, C C C E, I R$ and OP have negatively significant effects on the change of carbon intensity, meaning that the optimization of industrial structure and energy consumption structure in surrounding areas can slow down the increase of carbon intensity in the country, and the effects of B\&R Initiative on the neighboring regions of a country can help to lower the growth rate of carbon intensity in the country. Therefore, it can be concluded that the B\&R Initiative plays an important role in reducing the global carbon emissions, and thereby achieving the global GELC development; (6) The coefficient of $\sum_{j} w_{i, j} \Delta L C I_{j, t+1}$ is positive and significant, showing that the change of carbon intensity in a country will be influenced by those in the neighboring countries, which is due to the diffusion of carbon emissions. Therefore, reducing the carbon emissions is not a matter of one or several countries, but the common responsibility of all countries in the world, requiring all countries to strengthen cooperation and work together to achieve global GELC development. 
Table 11. Estimation results of conditional convergence of carbon intensity ( $p$-values in parentheses).

\begin{tabular}{|c|c|c|c|}
\hline Variable & SAR & SEM & SDM \\
\hline$L C I$ & $\begin{array}{c}-0.0940 \\
(0.0010)^{* * *}\end{array}$ & $\begin{array}{c}-0.0940 \\
(0.0009)^{* * *}\end{array}$ & $\begin{array}{c}-0.0956 \\
(0.0017) * * *\end{array}$ \\
\hline$L P G D P$ & $\begin{array}{c}0.0068 \\
(0.0989) *\end{array}$ & $\begin{array}{c}0.0073 \\
(0.0784) *\end{array}$ & $\begin{array}{c}0.0102 \\
(0.0244)^{* *}\end{array}$ \\
\hline$L P D$ & $\begin{array}{c}0.0267 \\
(0.0111)^{* *}\end{array}$ & $\begin{array}{c}0.0281 \\
(0.0116)^{* *}\end{array}$ & $\begin{array}{c}0.0518 \\
(0.0735) *\end{array}$ \\
\hline IS & $\begin{array}{l}-0.0272 \\
(0.0276) * *\end{array}$ & $\begin{array}{l}-0.0280 \\
(0.0266)^{* *}\end{array}$ & $\begin{array}{l}-0.0225 \\
(0.0387)^{* *}\end{array}$ \\
\hline$U R$ & $\begin{array}{c}0.0505 \\
(0.0215)^{* *}\end{array}$ & $\begin{array}{c}0.0471 \\
(0.0253) * *\end{array}$ & $\begin{array}{c}0.0739 \\
(0.0110)^{* *}\end{array}$ \\
\hline CCCE & $\begin{array}{l}-2.9108 \\
(0.0479) * *\end{array}$ & $\begin{array}{l}-2.6903 \\
(0.0523) *\end{array}$ & $\begin{array}{l}-0.3073 \\
(0.0947) *\end{array}$ \\
\hline IR & $\begin{array}{l}-0.0093 \\
(0.0455) * *\end{array}$ & $\begin{array}{l}-0.0082 \\
(0.0504) *\end{array}$ & $\begin{array}{l}-0.0107 \\
(0.0405)^{* *}\end{array}$ \\
\hline$O P$ & $\begin{array}{l}-0.0038 \\
(0.0509) *\end{array}$ & $\begin{array}{l}-0.0041 \\
(0.0468)^{* *}\end{array}$ & $\begin{array}{l}-0.0026 \\
(0.0657)^{*}\end{array}$ \\
\hline$\sum_{j} w_{i, j} L C I_{j, t}$ & - & - & $\begin{array}{c}0.0105 \\
(0.0780) *\end{array}$ \\
\hline$\sum_{j} w_{i, j} L P G D P_{j, t}$ & - & - & $\begin{array}{c}0.0005 \\
(0.0939) *\end{array}$ \\
\hline$\sum_{j} w_{i, j} L P D_{j, t}$ & - & - & $\begin{array}{l}-0.0244 \\
(0.4477)\end{array}$ \\
\hline$\sum_{j} w_{i, j} I S_{j, t}$ & - & - & $\begin{array}{l}-0.0062 \\
(0.0882)^{*}\end{array}$ \\
\hline$\sum_{j} w_{i, j} U R_{j, t}$ & - & - & $\begin{array}{c}0.0746 \\
(0.0274)^{* * *}\end{array}$ \\
\hline$\sum_{j} w_{i, j} C C C E_{j, t}$ & - & - & $\begin{array}{c}-6.5934 \\
(0.0340)^{* *}\end{array}$ \\
\hline$\sum_{j} w_{i, j} I R_{j, t}$ & - & - & $\begin{array}{l}-0.0101 \\
(0.0640) *\end{array}$ \\
\hline$\sum_{j} w_{i, j} O P_{j, t}$ & - & - & $\begin{array}{c}-0.0085 \\
(0.0342)^{* *}\end{array}$ \\
\hline$\sum_{j} w_{i, j} \Delta L C I_{j, t+1}$ & $\begin{array}{c}0.1233 \\
(0.0069)^{* * *}\end{array}$ & - & $\begin{array}{c}0.1261 \\
(0.0071)^{* * *}\end{array}$ \\
\hline$\sum_{j} w_{i, j} \epsilon_{j, t}$ & - & $\begin{array}{c}0.1292 \\
(0.0056)^{* * *}\end{array}$ & - \\
\hline Log-likelihood & 1446.8234 & 1447.0122 & 1449.1747 \\
\hline R-squared & 0.3192 & 0.3053 & 0.3485 \\
\hline Adjusted R-squared & 0.2146 & 0.2143 & 0.2185 \\
\hline sigma & 0.0175 & 0.0174 & 0.0174 \\
\hline \multicolumn{4}{|c|}{ Applicability tests of SDM } \\
\hline Method & \multicolumn{2}{|c|}{ Statistics } & Prob. \\
\hline Wald spatial lag & \multicolumn{2}{|c|}{8.5683} & $0.0034^{* * *}$ \\
\hline LR spatial lag & \multicolumn{2}{|c|}{7.4261} & $0.0064^{* * *}$ \\
\hline Wald spatial error & \multicolumn{2}{|c|}{4.5564} & $0.0328^{* *}$ \\
\hline LR spatial error & \multicolumn{2}{|c|}{4.8726} & $0.0273^{* *}$ \\
\hline
\end{tabular}

\section{Conclusions and Suggestions}

\subsection{Conclusions}

With the increasing global warming problem, achieving the global GELC development has become the consensus objective of the international community, of which the control of greenhouse gas, mainly $\mathrm{CO}_{2}$, is the most important. At present, the globalization of trade faces enormous challenges and 
the wave of "reverse globalization" continues to rise, causing serious troubles for the international community to cooperate in reduce carbon emissions. As a firm supporter of globalization, China has put forward the B\&R Initiative that benefits billions of people in more than 60 countries around the world and has built a very effective platform for international cooperation. B\&R Initiative proposed the concept of GELC development, which has to be in conformity with the theme of the global green energy transformation. Carbon intensity is an important indicator representing the degree of GELC development. Since the GELC development has become a global consensus, it is of great theoretical and practical significance to deeply understand the major conditions and differences in the carbon intensity of the B\&R countries, contributing to a better cooperation in the GELC economy. Based on this, the spatial panel theory is employed to examine the spatial distribution and convergence of carbon intensity in the B\&R countries. Specifically, this article first introduced the basic conditions of $B \& R$ countries and the main factors affecting carbon intensity, and then applied spatial analysis techniques to explore the spatial distribution of carbon intensities in 29 B\&R countries. Finally, considering spatial effects, the spatial panel convergence models including SAR, SEM and SDM were constructed and the empirical analysis was performed accordingly.

The results of the spatial distribution test showed that the global Moran's I of the 29 B\&R countries was significantly positive from 1995 to 2014, indicating a significant spatial agglomeration effect among these countries, that is, countries with high carbon intensity tend to be adjacent to countries with high carbon intensity, and vice versa. According to the changing trend of the global Moran's $I$, this paper selected six key time points (1995, 1998, 2002, 2006, 2010 and 2014) to draw the Moran scatter plots and calculated the local Moran's I of each country. The results showed that the number of HH-type agglomeration and LL-type agglomeration countries were decreasing, indicating that there was no significant optimization trend in the economic development modes of the B\&R countries. In addition, KAZ, UZB and RUS have had long-term significant positive radiation effects on the surrounding areas, meaning that the high carbon intensity of these countries will significantly increase the level of carbon intensity in the surrounding areas. JPN and KOR have had significant negative radiation effects on the surrounding areas, revealing that the low carbon intensity of these two countries will significantly promote the decline of carbon intensity in the surrounding areas. However, after 2010, the radiation effects of JPN and KOR were no longer significant, that is, none of the countries studied can significantly promote the decline of carbon intensity in the surrounding areas, indicating that the goal of achieving global GELC targets still has a long way to go.

The convergence test results showed that there were significant absolute convergence and conditional convergence in the B\&R countries, and the convergence speed of conditional convergence is faster, indicating that after considering the internal and external factors of different countries, the carbon intensity of each country will tend to the same steady-state value at a faster speed. Further, the conditional convergence results found that economic development and urbanization will promote the increase of carbon intensity in the country and neighboring countries, while the optimization of the industrial structure and energy consumption structure will help reduce the carbon intensity in the country and the surrounding areas. Besides, the investment rate and openness can promote the decline of carbon intensity growth rate in the country and adjacent areas, showing that the B\&R Initiative plays a positive role in boosting the GELC development. Moreover, the increase in population will increase the carbon intensity of a country but will not affect the carbon intensity of other countries. Finally, due to the proliferation of carbon emissions, the carbon intensity of the country will be positively affected by those of the surrounding areas, indicating that carbon emission reduction is a global governance issue that requires the participation of all countries, rather than the responsibility of a few countries.

\subsection{Suggestions}

The B\&R Initiative meets the theme of world development and can influence and promote the common development of countries along the route. The current global energy governance pattern 
is undergoing a major period of change, with main manifestations of energy supply and demand structure changes, global warming and climate change, and the geopolitical complexity of energy, resulting that the global energy economy needs to undergo profound adjustments. From the results of recent years, the $B \& R$ energy cooperation will undoubtedly become a new engine for global energy development. Under the current complex international situation of "reverse globalization", B\&R countries have a special significance in coping with climate change cooperation and building a GELC community, facing historical opportunities and challenges. China has made remarkable achievements in the field of GELC development, accumulating rich knowledge, experience, technology, talents and comprehensive solutions, and has the ability to play a more proactive role in global GELC cooperation. In order to better promote the cooperation of GELC economy under the B\&R framework, several policy recommendations are proposed from two aspects:

(1) As the advocate of the B\&R Initiative, China should incorporate the building of a GELC community into the framework and main agenda of B\&R. Firstly, on the basis of promoting the vision and actions of the $B \& R$ Initiative, China should explore and issue guidance on promoting the establishment of GELC communities in B\&R countries and strengthening international cooperation in combating climate change. Secondly, China should formulate key tasks and demand lists for the B\&R countries to jointly construct GELC communities. Specifically, under the framework of the "2030 Sustainable Development Agenda" and the "Paris Agreement", through extensive cooperation, the effective implementation of independent contributions by B\&R countries will be promoted, and the ability to cope with climate change will be enhanced. Based on full consideration of the development stage and national conditions of each country, China should focus on promoting the international cooperation and joint development in the fields of low-carbon infrastructure and industrial parks, green energy, low-carbon transportation, low-carbon products and service trade, low-carbon talent training and exchange and GELC technology R\&D. Thirdly, China should gradually improve the platforms, mechanisms and institutions for the construction of GELC communities in B\&R countries. Specifically, China should utilize the existing B\&R intergovernmental cooperation platform like Asia Infrastructure Investment Bank (AIIB), Silk Road Fund, and China South-South Cooperation Fund for Climate Change, and effectively combine the approaches like government assistance, international trade and investment and financing, to mobilize the participation of various stakeholders through a flexible cooperation model, so that people in the B\&R countries can share the achievements and benefits of the B\&R GELC community.

(2) To achieve the GELC development, China and the B\&R countries can work together to:

1) Establish the Asian Energy Cooperation Organization (AECO) and build the B\&R green power cooperation platform. The geopolitical relations of energy in China, Russia, the United States and Saudi Arabia have resulted that Asia, Europe and Africa have gradually become the global energy center, which will bring about significant risks to the B\&R green energy cooperation. Therefore, it is necessary to establish the AECO, which can establish a multilateral dialogue and coordination mechanism to coordinate the cooperation and contradictions among B\&R countries. Besides, the AECO can strengthen cooperation with international energy organizations such as the IEA and the Energy Charter, helping to enhance the security of regional cooperation and promote market integration and healthy competition. Moreover, China and $B \& R$ countries can build a $B \& R$ green power cooperation platform relying on established economic corridors, economic and technological cooperation zones and industrial development cooperation zones. In fact, some high-end green energy projects in key countries are constructed as the models of cooperation, which can effectively promote the GELC development.

2) Improve the $B \& R$ green financial mechanism and interface with international standards. The economic development level of the B\&R countries is generally low, but energy and electricity cooperation requires a lot of financial support. Therefore, it is quite necessary to establish a green financial system suitable for the B\&R Initiative. As a market-based institutional arrangement, green finance can leverage a variety of financial instruments and trading methods to provide financial 
leverage and green financial supply that matches the B\&R Initiative, which can improve the ecological environment when developing the economy and thereby achieving a GELC development. In the concrete operation of investment projects, it should adopt green financial policy measures to urge relevant financial institutions such as AIIB to effectively identify, measure, monitor and control environmental and social risks in investment and financing activities. At the same time, financial institutions such as AIIB and Silk Road Funds should link up with international financial standards and maintain cooperation with existing multilateral development banks to improve the investment feasibility of energy projects and should draw on and adopt the international good practices in environmental and social security to avoid vicious competition.

3) Vigorously promote infrastructure construction in $B \& R$ countries and realize interconnection between China and B\&R countries. Distance to a certain extent represents the cost of trade. The increase in the distance between China and B\&R countries has significantly reduced China's exports to these countries. Therefore, China and B\&R countries should jointly promote infrastructure construction in $B \& R$ countries, improving the distribution channels and logistics networks of import and export commodities by taking advantage of the interconnection of infrastructure facilities, which is of great significance for China and $B \& R$ countries to reduce the costs of trade transport and increase bilateral trade volume, trade efficiency, and trade potential. Besides, China should further deepen the economic restructuring and expand opening to the outside world, working with $B \& R$ countries to increase trade and investment facilitation to deepen economic and trade cooperation. China and B\&R countries should jointly improve the level of trade facilitation and reduce market access barriers to commodity flows, which can further increase trade potential. Different $B \& R$ countries have different comparative advantages and factor endowments. China should, in combination with the actual conditions of the economic development of these countries, deepen cooperation in the value chain to help them integrate into the international division of labor system and promote close cooperation in the entire industry chain, forming an GELC industrial network and economic cooperation system in which China and the $B \& R$ countries have complementary advantages.

Author Contributions: L.H. and F.Y.L. conceived and designed the research method used in this paper; X.Y. collected the data used for empirical analysis; F.Y.L. performed the empirical analysis and wrote the paper.

Acknowledgments: Thanks are due to the North China Electric Power University Library for providing detailed reference for our research and to L.B. for proofreading the language of this paper.

Conflicts of Interest: The authors declare no conflict of interest.

\section{References}

1. Bodansky, D. The United Nations framework convention on climate change: A commentary. YJIL 1993, 18, 451-558.

2. Schipper, E.L.F. Conceptual history of adaptation in the UNFCCC process. Rev. Eur. Comp. Int. Environ. Law 2006, 15, 82-92. [CrossRef]

3. He, J.; Su, M. Carbon Productivity Analysis to Address Global Climate Change. China Soft Sci. 2009, 10, $42-47$.

4. Chen, X.; Jiang, L.; Wang, C. Business process analysis and implementation strategies of greening logistics in appliances retail industry. Energy Procedia 2011, 5, 332-336.

5. Hamilton, M.R.; Herzog, H.J.; Parsons, J.E. Cost and US public policy for new coal power plants with carbon capture and sequestration. Energy Procedia 2009, 1, 4487-4494. [CrossRef]

6. Congress U.S. American Clean Energy and Security Act of 2009; HR 2454; US House of Representative: Washington, DC, USA, 2009.

7. Gomi, K.; Ochi, Y.; Matsuoka, Y. A systematic quantitative backcasting on low-carbon society policy in case of Kyoto city. Technol. Forecast. Soc. Chang. 2011, 78, 852-871. [CrossRef]

8. European Climate Foundation. A Practical Guide to a Prosperous, Low-Carbon Europe; Roadmap 2050; ECF: Brussels, Belgium, 2010. 
9. Lockwood, M. The political sustainability of climate policy: The case of the UK Climate Change Act. Glob. Environ. Chang. 2013, 23, 1339-1348. [CrossRef]

10. Ministry of Commerce of the People's Republic of China. France Announces National Low Carbon Strategy. Available online: http:/ / www.mofcom.gov.cn/article/i/jyjl/m/201511/20151101167164.shtml (accessed on 18 November 2015).

11. Lauber, V.; Jacobsson, S. The politics and economics of constructing, contesting and restricting socio-political space for renewables-The German Renewable Energy Act. Environ. Innov. Soc. Transit. 2016, 18, 147-163. [CrossRef]

12. Phoenix Finance. The United States Announced that it has Withdrawn from the "Paris Agreement": Little Impact on China and Global low-Carbon Development. Available online: http://finance.ifeng. com/a/20170603/15426022_0.shtml (accessed on 3 June 2017).

13. Bai, Y.; Wang, S. Deep Background and Geopolitical Strategy of Silk-road Economic Belt. Reform 2014, 3, 64-73.

14. Zhu, C. 21st Century Maritime Silk Road; India's Ocean; Springer: Singapore, 2018; pp. 135-161.

15. Ferdinand, P. Westward ho-The China dream and 'one belt, one road': Chinese foreign policy under Xi Jinping. Int. Aff. 2016, 92, 941-957. [CrossRef]

16. National Development and Reform Commission; Ministry of Foreign Affairs; Ministry of Commerce of the People's Republic of China with State Council authorization. Vision and Action for the Promotion of the Silk Road Economic Belt and the 21st Century Maritime Silk Road. Available online: http:/ /www.mofcom.gov. cn/article/i/jyjl/1/201504/20150400933572.shtml (accessed on 6 April 2015).

17. Ministry of Environmental Protection; Ministry of Foreign Affairs; National Development and Reform Commission; Ministry of Commerce of the People's Republic of China with State Council authorization. Guiding Opinions on Promoting the Construction of the Green Belt and Road. Available online: http: / /www.zhb.gov.cn/gkml/hbb/bwj/201705/t20170505_413602.htm (accessed on 26 April 2017).

18. Suocheng, D.; Zehong, L.; Yu, L.; Shi, G.; Yu, H.; Wang, J.; Li, J.; Mao, Q.; Huang, Y. Resources, environment and economic patterns and sustainable development modes of the Silk Road Economic Belt. J. Resour. Ecol. 2015, 6, 65-72. [CrossRef]

19. Bond, T.C.; Bhardwaj, E.; Dong, R.; Jogani, R.; Jung, S.; Roden, C.; Streets, D.G.; Trautmann, N.M. Historical emissions of black and organic carbon aerosol from energy-related combustion, 1850-2000. Glob. Biogeochem. Cycles 2007, 21, 1-16. [CrossRef]

20. He, K.; Huo, H.; Zhang, Q.; He, D.; An, F.; Wang, M.; Walsh, M.P. Oil consumption and $\mathrm{CO}_{2}$ emissions in China's road transport: Current status, future trends, and policy implications. Energy Policy 2005, 33, 1499-1507. [CrossRef]

21. Lund, H. Renewable energy strategies for sustainable development. Energy 2007, 32, 912-919. [CrossRef]

22. Xie, H.; Chen, Q.; Lu, F.; Wu, Q.; Wang, W. Spatial-temporal disparities, saving potential and influential factors of industrial land use efficiency: A case study in urban agglomeration in the middle reaches of the Yangtze River. Land Use Policy 2018, 75, 518-529. [CrossRef]

23. Swaine, M.D. Chinese views and commentary on the 'One Belt, One Road' initiative. China Leadersh. Monit. 2015, 47, 1-24.

24. National Energy Administration. Vision and Action for Promoting Energy Cooperation in the Silk Road Economic Belt and the 21st Century Maritime Silk Road. Available online: http:/ / www.nea.gov.cn/201705/12/c_136277473.htm (accessed on 12 May 2017).

25. Wang, Y. Offensive for defensive: The belt and road initiative and China's new grand strategy. Pac. Rev. 2016, 29, 455-463. [CrossRef]

26. Chai, Q.; Qi, Y.; Fu, S. Promote the establishment of low-carbon communities in Belt and Road countries. China Dev. Obs. 2017, Z2, 35-40.

27. Adelman, I. An econometric analysis of population growth. Am. Econ. Rev. 1963, 53, 314-339.

28. Resti, A. Evaluating the cost-efficiency of the Italian banking system: What can be learned from the joint application of parametric and non-parametric techniques. J. Bank. Financ. 1997, 21, 221-250. [CrossRef]

29. Dijkgraaf, E.; Vollebergh, H.R.J. A test for parameter homogeneity in $\mathrm{CO}_{2}$ panel EKC estimations. Environ. Resour. Econ. 2005, 32, 229-239. [CrossRef]

30. Attanasio, O.P.; Picci, L.; Scorcu, A.E. Saving, growth, and investment: A macroeconomic analysis using a panel of countries. Rev. Econ. Stat. 2000, 82, 182-211. [CrossRef] 
31. Hansen, B.E. Threshold effects in non-dynamic panels: Estimation, testing, and inference. J. Econom. 1999, 93, 345-368. [CrossRef]

32. Christopoulos, D.K.; Tsionas, E.G. Financial development and economic growth: Evidence from panel unit root and cointegration tests. J. Dev. Econ. 2004, 73, 55-74. [CrossRef]

33. Kiviet, J.; Pleus, M.; Poldermans, R. Accuracy and Efficiency of Various GMM Inference Techniques in Dynamic Micro Panel Data Models. Econometrics 2017, 5, 14. [CrossRef]

34. Elhorst, J.P. Spatial Panel Data Models; Spatial Econometrics; Springer: Berlin/Heidelberg, Germany, 2014; pp. 37-93.

35. Zhang, N.; Liu, Z.; Zheng, X.; Xue, J. Carbon footprint of China's belt and road. Science 2017, $357,1107$. [CrossRef] [PubMed]

36. Len, C. China's 21st Century Maritime Silk Road initiative, energy security and SLOC access. Marit. Aff. 2015, 11, 1-18. [CrossRef]

37. Liu, Y.; Zhou, Y.; Wu, W. Assessing the impact of population, income and technology on energy consumption and industrial pollutant emissions in China. Appl. Energy 2015, 155, 904-917. [CrossRef]

38. Huang, H.; Yu, X. Building the Global Value Chain Based on the "Belt and Road" Initiative. Economist 2017, 3, 32-39.

39. Huang, Y. Understanding China's Belt \& Road Initiative: Motivation, framework and assessment. China Econ. Rev. 2016, 40, 314-321.

40. Callahan, W.A. China's "Asia Dream" The Belt Road Initiative and the new regional order. Asian J. Comp. Polit. 2016, 1, 226-243. [CrossRef]

41. Anand, B. Reverse Globalization by Internationalization of SME's: Opportunities and Challenges Ahead. Procedia-Soc. Behav. Sci. 2015, 195, 1003-1011. [CrossRef]

42. Rodrik, D. Too Late to Compensate Free Trade's Losers. Proj. Synd. 2017, 11, 1-3.

43. Xinhua Net. Xi Jinping Attends the Opening Ceremony of the 2018 Annual Conference of the Boao Forum for Asia and Delivers a Keynote Speech. Available online: http:/ / www.xinhuanet.com/politics/leaders/ 2018-04/10c_1122660064.htm (accessed on 10 April 2018).

44. Zou, J.; Liu, C.; Yin, G.; Tang, Z. Spatial patterns and economic effects of China's trade with countries along the Belt and Road. Prog. Geogr. 2015, 34, 598-605.

45. Yu, H. Motivation behind China's 'One Belt, One Road' initiatives and establishment of the Asian infrastructure investment bank. J. Contemp. China 2017, 26, 353-368. [CrossRef]

46. Acaravci, A.; Erdogan, S. The Convergence Behavior of $\mathrm{CO}_{2}$ Emissions in Seven Regions under Multiple Structural Breaks. Int. J. Energy Econ. Policy 2016, 6, 575-580.

47. Goh, T.; Ang, B.W.; Su, B.; Wang, H. Drivers of stagnating global carbon intensity of electricity and the way forward. Energy Policy 2018, 113, 149-156. [CrossRef]

48. Zhang, Y.J.; Hao, J.F.; Song, J. The $\mathrm{CO}_{2}$ emission efficiency, reduction potential and spatial clustering in China's industry: Evidence from the regional level. Appl. Energy 2016, 174, 213-223. [CrossRef]

49. Roberts, J.T.; Grimes, P.E. Carbon intensity and economic development 1962-1991: A brief exploration of the environmental Kuznets curve. World Dev. 1997, 25, 191-198. [CrossRef]

50. Su, B.; Ang, B.W. Multiplicative decomposition of aggregate carbon intensity change using input-output analysis. Appl. Energy 2015, 154, 13-20. [CrossRef]

51. Greening, L.A.; Davis, W.B.; Schipper, L. Decomposition of aggregate carbon intensity for the manufacturing sector: Comparison of declining trends from 10 OECD countries for the period 1971-1991. Energy Econ. 1998, 20, 43-65. [CrossRef]

52. Zhang, Y. Economic Development Pattern Change Impact on China's Carbon Intensity. Econ. Res. J. 2010, 4, 120-133.

53. Lindmark, M. Patterns of historical $\mathrm{CO}_{2}$ intensity transitions among high and low-income countries. Explor. Econ. Hist. 2004, 41, 426-447. [CrossRef]

54. Lanne, M.; Liski, M. Trends and breaks in per-capita carbon dioxide emissions, 1870-2028. Energy J. 2004, 25, 41-65. [CrossRef]

55. Zhou, P.; Ang, B.W.; Han, J.Y. Total factor carbon emission performance: A Malmquist index analysis. Energy Econ. 2010, 32, 194-201. [CrossRef]

56. Ang, B.W. Is the energy intensity a less useful indicator than the carbon factor in the study of climate change? Energy Policy 1999, 27, 943-946. [CrossRef] 
57. Wang, S.; Yu, W. Sensitivity analysis of primary energy consumption structural change and carbon intensity. Resour. Sci. 2013, 35, 1438-1446.

58. Haining, R.; Wise, S.; Ma, J. Exploratory spatial data analysis. J. R. Stat. Soc. Ser. D 1998, 47, 457-469. [CrossRef]

59. Yu, H. The influential factors of China's regional energy intensity and its spatial linkages: 1988-2007. Energy Policy 2012, 45, 583-593. [CrossRef]

60. Tiefelsdorf, M.; Boots, B. A note on the extremities of local Moran's Iis and their impact on global Moran's I. Geogr. Anal. 1997, 29, 248-257. [CrossRef]

61. Anselin, L.; Bera, A.K.; Florax, R.; Yoon, M.J. Simple diagnostic tests for spatial dependence. Reg. Sci. Urban Econ. 1996, 26, 77-104. [CrossRef]

62. Anselin, L. Local indicators of spatial association-LISA. Geogr. Anal. 1995, 27, 93-115. [CrossRef]

63. Barro, R.J.; Sala-i-Martin, X. Convergence. J. Polit. Econ. 1992, 100, 223-251. [CrossRef]

64. Slaughter, M.J. Per Capita Income Convergence and the Role of International Trade. National Bureau of Economic Research. Available online: http:/ / www.nber.org/papers/w5897 (accessed on 10 June 2018).

65. Liddle, B. Revisiting world energy intensity convergence for regional differences. Appl. Energy 2010, 87, 3218-3225. [CrossRef]

66. Bichara, J.S. Business cycle convergence and trade: Brazil and China in a changing world. J. Econ. Policy Reform 2015, 19, 39-64. [CrossRef]

67. Pettersson, F.; Maddison, D.; Acar, S.; Patrik, S. Convergence of carbon dioxide emissions: A review of the literature. Int. Rev. Environ. Resour. Econ. 2014, 7, 141-178. [CrossRef]

68. Cakan, C.; Altay, B.; Mursaleen, M. The $\sigma$-convergence and $\sigma$-core of double sequences. Appl. Math. Lett. 2006, 19, 1122-1128. [CrossRef]

69. Young, A.T.; Higgins, M.J.; Levy, D. Sigma convergence versus beta convergence: Evidence from US county-level data. J. Money Credit Bank. 2008, 40, 1083-1093. [CrossRef]

70. Panopoulou, E.; Pantelidis, T. Club convergence in carbon dioxide emissions. Environ. Resour. Econ. 2009, 44, 47-70. [CrossRef]

71. Galor, O. Convergence? Inferences from theoretical models. Econ. J. 1996, 106, 1056-1069. [CrossRef]

72. Anselin, L. Lagrange multiplier test diagnostics for spatial dependence and spatial heterogeneity. Geogr. Anal. 1988, 20, 1-17. [CrossRef]

73. Wu, Y.M. A spatial econometric model and its application to research \& development and regional innovation. J. Quant. Tech. Econ. 2006, 5, 74-85.

74. Kelejian, H.H.; Prucha, I.R. A generalized spatial two-stage least squares procedure for estimating a spatial autoregressive model with autoregressive disturbances. J. Real Estate Financ. Econ. 1998, 17, 99-121. [CrossRef]

75. Baltagi, B.H.; Song, S.H.; Koh, W. Testing panel data regression models with spatial error correlation. J. Econom. 2003, 117, 123-150. [CrossRef]

76. Elhorst, J.P.; Fréret, S. Evidence of political yardstick competition in France using a two-regime spatial Durbin model with fixed effects. J. Reg. Sci. 2009, 49, 931-951. [CrossRef]

77. Mur, J.; Angulo, A. The spatial Durbin model and the common factor tests. Spat. Econ. Anal. 2006, 1, $207-226$. [CrossRef]

78. Ehrlich, P.R.; Holdren, J.P. Impact of population growth. Science 1971, 171, 1212-1217. [CrossRef] [PubMed]

79. York, R.; Rosa, E.A.; Dietz, T. STIRPAT, IPAT and ImPACT: Analytic tools for unpacking the driving forces of environmental impacts. Ecol. Econ. 2003, 46, 351-365. [CrossRef]

80. Zhao, A.; $\mathrm{Wu}$, C.Y. Analysis of decomposition of influencing factors of variation in $\mathrm{CO}_{2}$ emission of China: Based on improved Kaya identity and LMDI method. Soft Sci. 2010, 24, 55-59.

81. O'Mahony, T. Decomposition of Ireland's carbon emissions from 1990 to 2010: An extended Kaya identity. Energy Policy 2013, 59, 573-581.

82. Feng, T.; Sun, L.; Zhang, Y. The relationship between energy consumption structure, economic structure and energy intensity in China. Energy Policy 2009, 37, 5475-5483. [CrossRef]

83. Jinke, L.; Hualing, S.; Dianming, G. Causality relationship between coal consumption and GDP: Difference of major OECD and non-OECD countries. Appl. Energy 2008, 85, 421-429. [CrossRef] 
84. Guo, J.; Chai, J.; Xi, Y. Analysis of influences between the energy structure change and energy intensity in China. China Popul. Resour. Environ. 2008, 18, 38-43.

85. Li, X.; Wang, Y. A Study on the Convergence of Carbon Productivity in the Major Countries of The Belt and Road and the Analysis of its Influencing Factors. Wuhan Univ. J. (Soc. Sci.) 2017, 70, 58-76. 